Artículo de Investigación/Research Article

TecnoLógicas

ISSN-p 0123-7799

ISSN-e 2256-5337

Vol. 23, No. 48, pp. 55-81

Mayo-agosto de 2020

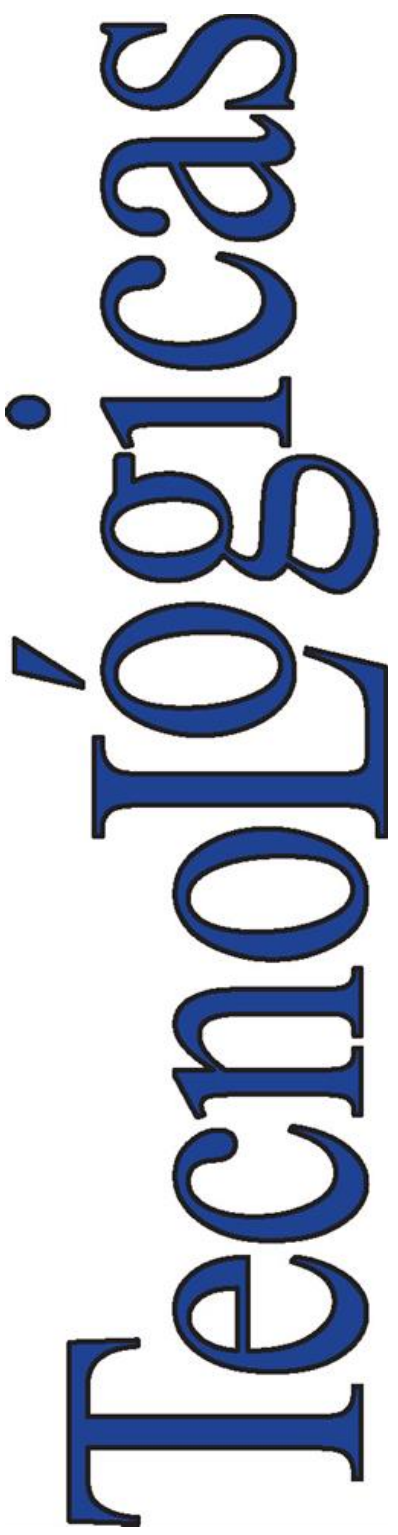

\title{
Validación de un modelo de logística inversa para la recuperación de los RAEE de la ciudad de Cali, basado en el Pensamiento Sistémico usando una simulación con Dinámica de Sistemas
}

\section{Validation of a Model of Reverse Logistics for the recovery of WEEE from the city of Cali, based on the Systemic Thinking using a simulation of System Dynamics}

Jorge E. Calpa-Oliva@ $\mathbf{Q}^{1}$

Recibido: 22 de julio de 2019

Aceptado: 23 de enero de 2020

Cómo citar / How to cite

J. E. Calpa-Oliva, "Validación de un modelo de logística inversa para la recuperación de los RAEE de la ciudad de Cali, basado en el Pensamiento Sistémico usando una simulación con Dinámica de Sistemas", TecnoLógicas, vol. 23, no. 48, pp. 55-81, 2020. https://doi.org/10.22430/22565337.1418

(C) Instituto Tecnológico Metropolitano Este trabajo está licenciado bajo una Licencia Internacional Creative Commons Atribución (CC BY-NC-SA)

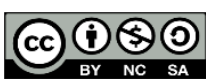

1 MSc. en Ingeniería Industrial, Departamento de Operaciones y Sistemas, Facultad de Ingeniería, Universidad Autónoma de Occidente, Cali-Colombia, jcalpa@uao.edu.co 
Validación de un modelo de logística inversa para la recuperación de los RAEE de la ciudad de Cali, basado en el Pensamiento Sistémico usando una simulación con Dinámica de Sistemas

\section{Resumen}

El proceso de recuperación de Residuos de Aparatos Eléctricos y Electrónicos (RAEE) crece día a día. Desde el punto de vista académico y empresarial, este presenta una notable importancia económica, ambiental y tecnológica, y su estudio en nuestro país aún está en su etapa inicial. El presente estudio tiene como objetivo la validación y entendimiento de un modelo de logística inversa para la recuperación de RAEE a partir del diseño y la construcción de un modelo de simulación continua basado en la perspectiva del pensamiento sistémico soportado con la dinámica de sistemas; Las proyecciones de este estudio se construyeron con base en la información del proceso de recuperación en forma artesanal que utilizan empresas de la región, así como empresas del sector que poseen niveles aceptables de tecnología para realizar las actividades de recuperación. Puntualmente, se tomó como referencia una empresa del sector, que presenta el proceso de recuperación del plástico PET, el cual es adaptable a cualquier proceso de recuperación de diferentes tipos de plástico. Esta primera aproximación permitió iniciar el proceso para la formulación de un sistema de logística inversa para el tratamiento de los residuos que generan los aparatos de las tecnologías de la información. Los resultados obtenidos en el modelo propuesto muestran comportamientos coherentes y este puede ser usado en diferentes escenarios y en otros procesos productivos para la recuperación de los RAEE. El estudio del sistema para la Recuperación de Aparatos Eléctricos y Electrónicos presenta altos niveles de variabilidad e incertidumbre, que lo convierten en algo complejo; esto obliga a la utilización de herramientas consideradas robustas, como la dinámica de sistemas, para su análisis.

\section{Palabras clave}

Pensamiento sistémico, dinámica de sistemas, recuperación aparatos eléctricos y electrónicos, logística inversa, simulación dinámica de sistemas.

\section{Abstract}

The recovery of waste electrical and electronic equipment (WEEE) continues to grow every day. From the academic and business perspective, this process has gained a remarkable economic, environmental, and technological importance. In Colombia, however, its study is still incipient. In this paper, we aim to understand and validate a reverse logistics model for the recovery of waste electrical and electronic equipment (WEEE) based on the design and construction of a continuous simulation strategy. This strategy adopts the systems thinking approach supported by system dynamics. The projections in this study were calculated using information about the traditional recovery processes implemented by companies in the region and about companies in the sector that use acceptable technologies to carry out recovery activities. In particular our baseline model was a company that recycles $\mathrm{PET}$ plastic and whose recycling process can be adapted to different types of plastic. This first step allowed us to develop a reverse logistics system to manage the waste generated by discarded IT devices. Our findings showed consistent behaviors and suggest that the proposed model can be used in different scenarios and other production processes for WEEE recovery. The study of WEEE recovery systems is highly variable and uncertain, which makes it a complex task. Therefore, tools that are considered robust, such as system dynamics, must be used for that purpose.

\section{Keywords}

Systems thinking, system dynamics, electrical and electronic equipment recovery, reverse logistics, dynamic system simulation. 
Validación de un modelo de logística inversa para la recuperación de los RAEE de la ciudad de Cali, basado en el Pensamiento Sistémico usando una simulación con Dinámica de Sistemas

\section{INTRODUCCIÓN}

En las últimas décadas, la industria electrónica y el incremento en el uso de las Tecnologías de la Información y las Comunicaciones (TIC) han revolucionado al mundo y han generado Residuos de Aparatos Eléctricos y Electrónicos (RAEE, o en inglés wase). Estos provienen del uso de diversas tecnologías en áreas como la medicina, la movilidad, la educación, la salud, el suministro de alimentos, la comunicación, la seguridad, la protección del medio ambiente y la cultura [1]. A su vez, estos se vuelven un problema ambiental, puesto que pueden llegar a contener componentes tóxicos como metales pesados y retardantes de llama bromados, ya que están constituidos con metales como hierro, cobre, aluminio y oro.

A la par, los RAEE y los AEE (Aparatos Eléctricos y Electrónicos) se han convertido en algunos de los residuos de más rápido crecimiento a nivel mundial.

Particularmente, en América Latina, su crecimiento se ha incrementado producto del aumento de la población y la urbanización de esta zona. Lo anterior está asociado a los escasos programas de gestión regulados para hacer una buena disposición de estos productos al final de su vida útil, como ocurre con los computadores y otros dispositivos electrónicos que no son recolectados ni tratados de una forma amigable con el medio ambiente, pues sus materiales y componentes son a menudo extraídos de una forma primitiva e ineficiente [2].

Desde principios en 2007, el Instituto Federal Suizo de Prueba e Investigación en materiales (EMPA) ha adelantado investigaciones en colaboración con el Centro Nacional de Producción más Limpia y Tecnologías Ambientales CNPMLTA (Medellín, Colombia). Algunos de los primeros resultados de estos estudios se encuentran en dos diagnósticos nacionales sobre RAEE [3]. En el primer diagnóstico, se estima que entre 1998 y 2007, Colombia generó aproximadamente 45000 toneladas de computadores obsoletos, que incluyen de 6000 a 9000 toneladas de computadores alcanzaron el final de su vida útil durante el año 2007.

De acuerdo con la información reportada al Sistema Único de Información de Servicios Públicos (SUI), aún existe un porcentaje importante de residuos que se manejan de manera inadecuada; a pesar de esto, se ha avanzado en la implementación de políticas, y programas que armonizan diferentes elementos y esquemas dinámicos capacitados para responder a las diversas necesidades y avances tecnológicos. La disposición final de los residuos sólidos plásticos genera un impacto ambiental, en tanto que son vaciados sobre vertederos a cielo abierto.

Esta práctica es muy común en algunos de los municipios de Colombia y ha obligado a establecer estrategias para aquellas regiones de difícil gestión y donde los problemas de disposición final inadecuada persisten [4].

El plástico está presente en diferentes productos como partes internas y cromadas de automóviles; en jugueterías, como fichas de lego; en equipos eléctricos y electrónicos como carcasas de televisores, radios, fax, celulares, computadores, ratones e impresoras y en elementos de oficina como grapadoras y carpetas pesadas. Cabe aclarar que este último tipo de residuos se compone de varios tipos de plásticos como: PS poliestireno, PE AD polietileno de alta densidad, PE BD polietileno de baja densidad, PP polipropileno, PP T20 polipropileno con talco, PC policarbonato, ABS-PC abs + policarbonato, PMMA metacrilato, PA poliamida, PET polietilentereftalato, entre otros.

La asociación de operadores móviles y compañías del sector GSMA-TM, en su informe del mes de febrero del año 2015 indica que, según estudios realizados por la Universidad de las Naciones Unidas (UNU), nuestro país ha generado entre los años 
Validación de un modelo de logística inversa para la recuperación de los RAEE de la ciudad de Cali, basado en el Pensamiento Sistémico usando una simulación con Dinámica de Sistemas

2009 y 2015, 884 mil toneladas de RAEE, lo que implica un crecimiento del 40,7\% [5].

En Cali, el Departamento Administrativo de Planeación Municipal [6] reportó como proyección para el periodo 20272664995 habitantes, que pueden producir en promedio 2712 toneladas al día de residuos sólidos en la ciudad de Cali.

En la actualidad, es poco lo documentado en la literatura local $\mathrm{y}$ nacional en relación con modelos de logística inversa que permitan el estudio de alternativas para la recuperación de residuos plásticos provenientes de RAEE.

Se pudo encontrar un artículo de varios autores que estudia la recuperación de RAEE tipo 3, buscando analizar e identificar el proceso de gestión y recuperación de este tipo de RAEE en la ciudad de Bogotá [7]; además, existe una tesis de maestría en gestión ambiental en la Universidad Javeriana sede Bogotá, que busca integrar a los productores participantes en la gestión nacional de los RAEE [8].

A nivel nacional existen empresas legalmente constituidas para realizar procesos de recolección y acopio como: Gaia Vitare, Lasea soluciones, Belmont trading y Computadores para Educar, ubicadas en la ciudad de Bogotá. Además; está C. I. Recycables en Cartagena, y ASEI Ltda., eCycling S. A. S y Codesarrollo, en Medellín. Las anteriores fundaciones adelantan un proceso de desensamble, recuperación y exportación de elementos de AEE. En la ciudad de Cali, la empresa que lidera el reciclaje, aprovechamiento $\mathrm{y}$ disposición de excedentes industriales de los aparatos es Lito Ltda. Esta se encarga del acopio, tratamiento y aprovechamiento económico de las materias primas, especialmente de los materiales cerámicos, metálicos y poliméricos.

Por otra parte, el cierre del antiguo sitio de disposición final ubicado en Navarro tuvo como resultado la puesta en marcha de un nuevo relleno sanitario ubicado en el municipio de Yotoco; este redireccionó el tradicional esquema centrado en el enterramiento de los residuos hacia la gestión integral de los mismos, definiendo y poniendo en práctica alternativas de aprovechamiento, tratamiento y disposición final que incorporen el desarrollo de nuevas formas de empleo.

En los anteriores proyectos se concentra la aplicación de nuevas tecnologías y dinámicas de participación y coordinada de los diferentes actores que hacen parte de la cadena del reciclaje, del sector industrial, del sector académico y la sociedad en general, entorno al desarrollo de una cultura de separación en la fuente y el reciclaje.

En Cali, se puede identificar una serie de cadenas de reciclaje por las cuales pasan los residuos. Como se evidencia en la Fig. 1, cada uno de los tipos de generadores de RAEE inicia su cadena de reciclaje de una manera diferente. Generalmente, en el sector público la salida de estos RAEE se lleva a cabo a través de subastas en las que diferentes compradores se quedan con ellos; en el sector privado, muchos de los RAEE generados en estas empresas son entregados a los gestores para que les den un manejo adecuado (servicio por el cual se paga un valor), aunque otros se entregan directamente a recicladores informales.

Cabe aclarar que, en los hogares, el medio de salida de los RAEE es, generalmente, a través de la empresa de aseo, o estos son entregados a recicladores de la calle. Sin embargo, constantemente se presentan variaciones entre los diferentes actores de la cadena. Un aspecto importante encontrado en la ciudad de Cali es que las personas dueñas de los negocios informales están pensando en entrar a la formalidad, lo que se debe a que las empresas públicas y privadas generadoras de este tipo de residuos buscan que los receptores estén autorizados por la autoridad ambiental para gestionar residuos peligrosos. Dicha seguridad les garantiza una gestión más adecuada. 
Validación de un modelo de logística inversa para la recuperación de los RAEE de la ciudad de Cali, basado en el Pensamiento Sistémico usando una simulación con Dinámica de Sistemas

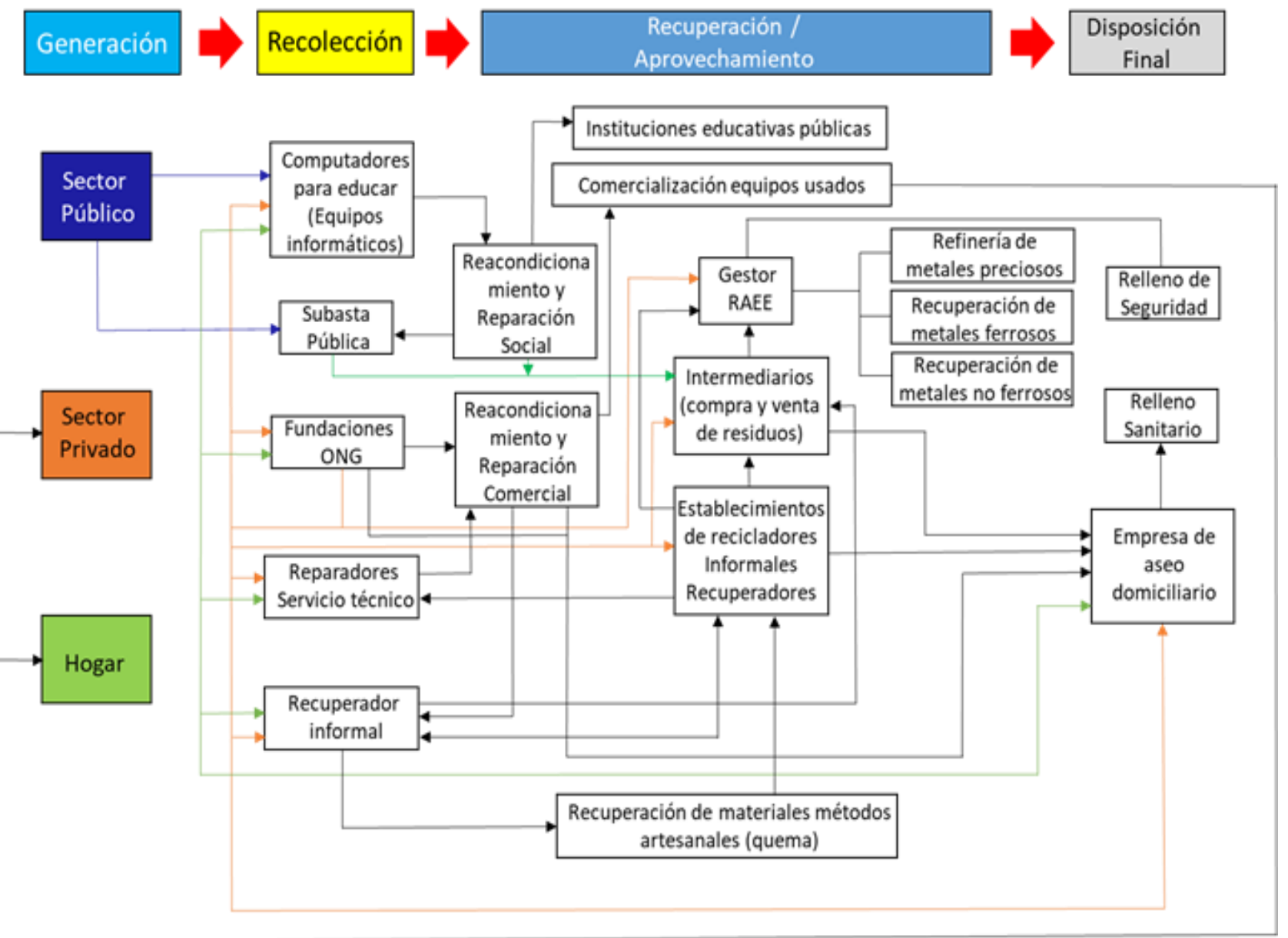

Fig.1. Flujograma de la situación actual de la gestión de los residuos de aparatos eléctricos y electrónicos en la ciudad de Cali. Fuente: [2].

Los negocios de reciclaje de RAEE que funcionan de manera informal están concentrados en el centro de la ciudad, tal como los negocios familiares e independientes; el desguace de las piezas se hace manual y posteriormente se comercializan a empresas o a negocios formales que se encargan de recuperarlos.

En consecuencia, se hace necesario instaurar lineamientos que faciliten $y$ fortalezcan la gestión de los residuos sólidos, a partir de la base de su generación hasta la correcta disposición final. Así mismo, es necesario establecer esquemas regionales para su manejo, aprovechamiento o cofinanciación, bajo criterios reales de viabilidad, eficiencia, optimización y calidad. El cumplimiento de estos aspectos involucra el deber de la academia de diseñar tales sistemas y, por supuesto, el diseño de herramientas que permitan evaluar los futuros comportamientos derivados de los componentes y las relaciones entre los elementos que se planteen en dichos diseños.

La sostenibilidad se ha convertido en una preocupación mundial, en una suerte de motivación para revisar las operaciones de la cadena de suministro con el fin de validar sus impactos ambientales $\mathrm{y}$ sociales. Este marco ha dado lugar al concepto de Gestión Sostenible de la Cadena de Suministro (SSCM), que básicamente se refiere a la gestión de los materiales, la información y los flujos de capital, así como a la cooperación entre empresas a lo largo de la cadena de 
Validación de un modelo de logística inversa para la recuperación de los RAEE de la ciudad de Cali, basado en el Pensamiento Sistémico usando una simulación con Dinámica de Sistemas

suministro, teniendo en cuenta las dimensiones económicas, ambientales $\mathrm{y}$ sociales, con base en los requisitos del cliente y de los interesados.

Todas estas complejidades han dado lugar a la gestión de la cadena logística, que consiste en organizar adecuadamente todo el proceso, desde la adquisición de materias primas hasta la entrega del producto terminado al cliente, todo en el lugar apropiado, en el momento oportuno y del modo adecuado. En la actualidad, las organizaciones están obligadas a participar de una cadena de suministro cuya estructura tiene dos dimensiones: la horizontal, representada por el número de eslabones o etapas que integran la cadena, y la vertical, correspondiente al número de miembros o empresas que constituyen cada eslabón.

Son varias las definiciones de logística, sin embargo, para el marco de este proyecto se tendrán como referencia:

-Las siete CES, esto consiste en el aseguramiento de las disponibilidades del producto correcto, en la cantidad correcta, en las condiciones correctas, en el sitio correcto, a la hora correcta, para el cliente correcto y al precio correcto [9].

-La planificación, implementación y control eficiente y efectivo del flujo directo e inverso, además del almacenamiento de bienes, servicios e información relacionada, desde el origen al cliente, con el fin de satisfacer sus necesidades [10].

Pero ¿qué sucede con el producto que el consumidor final retorna a la cadena al considerarlo defectuoso, o al que desecha por haber cumplido su ciclo de vida, entre otras razones? Surge entonces la logística inversa como una herramienta adecuada para gestionar correctamente los flujos y llevarlos aguas arriba (flujos inversos de productos) dentro de la cadena de suministro.

La problemática medio ambiental y la legislación, cada vez más exigente, han obligado a las empresas a generar estrategias de diseño de productos que minimicen el impacto ambiental, considerando su ciclo de vida y sus componentes, con el fin de utilizarlos nuevamente en procesos productivos de la misma empresa o incluso de otras organizaciones. Esto ocurre con el fin de fabricar ya sea el mismo producto $u$ otro tipo de productos, lo que se constituye, en muchos casos, como una ventaja competitiva para las organizaciones.

La logística inversa comprende el flujo de productos, información y dinero desde el punto de uso (distribuidores- clientes) hasta el de origen o reproceso (empresaproveedor). Lo anterior es contrario a la dirección tradicional de la cadena de suministro, que comprende desde el punto de origen hasta el punto final (Fig. 2).

En la Tabla 1, para el caso de estudio, se consideran productos que han finalizado su ciclo de vida, como los electrónicos.

En resumen, las actividades básicas de logística inversa para los residuos eléctricos y electrónicos se pueden agrupar en la Fig. 3. 
Validación de un modelo de logística inversa para la recuperación de los RAEE de la ciudad de Cali, basado en el Pensamiento Sistémico usando una simulación con Dinámica de Sistemas

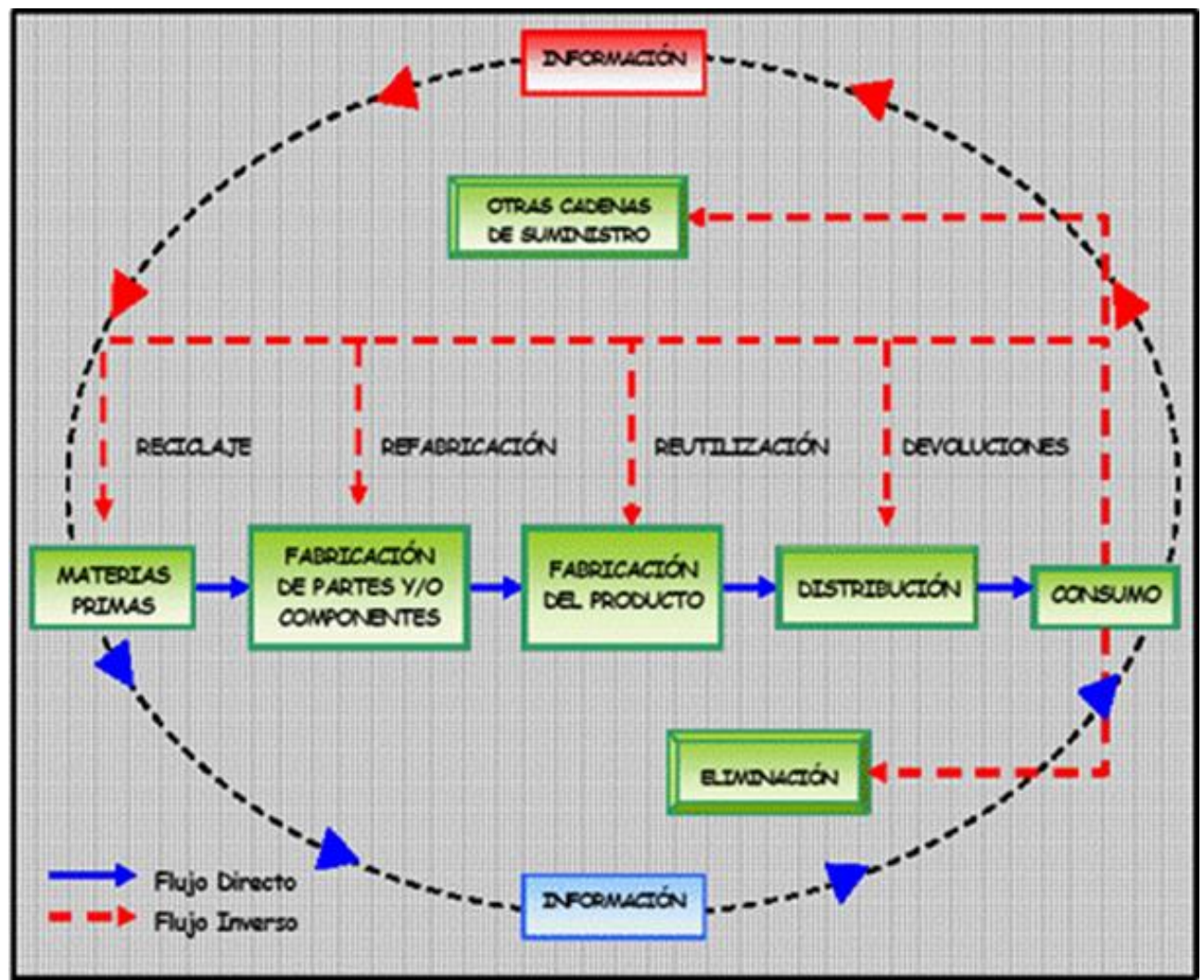

Fig. 2. Flujos en el sistema de logística inversa. Fuente: [11].

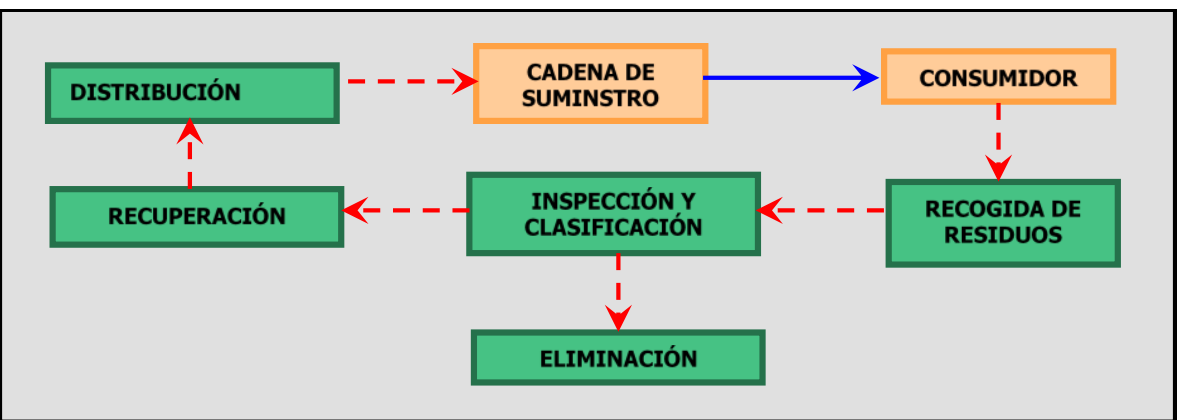

Fig. 3. Actividades de la logística inversa. Fuente: elaboración propia.

Tabla 1. Razones para la introducción de material al flujo inverso, según tipo y origen. Fuente: [12].

\begin{tabular}{|c|c|c|}
\hline & Fuente del flujo inverso & \\
\hline & Miembros de la cadena de suministro & Usuarios finales \\
\hline \multirow{5}{*}{$\begin{array}{l}\text { Dn } \\
\stackrel{0}{0} \\
0 \\
0 \\
0 \\
0 \\
0\end{array}$} & Mercancía de primera calidad & Producto defectuoso no \\
\hline & Retornos para equilibrar las existencias & deseado \\
\hline & Retorno del mercado & Retornos en garantía \\
\hline & Fin de vida/estación & Destrucción medio \\
\hline & Daño en el transporte & ambiental \\
\hline \multirow{3}{*}{ 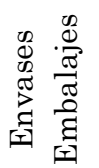 } & & Reutilización \\
\hline & Embalajes/envases reutilizables & Reciclaje \\
\hline & Requerimientos de destrucción & $\begin{array}{l}\text { Restricciones de } \\
\text { destrucción }\end{array}$ \\
\hline
\end{tabular}


Validación de un modelo de logística inversa para la recuperación de los RAEE de la ciudad de Cali, basado en el Pensamiento Sistémico usando una simulación con Dinámica de Sistemas

En la Tabla 2 se presenta un resumen de las actividades de la logística inversa, teniendo en cuenta el producto, el envase y embalaje.

Es importante clasificar la cadena inversa con el fin de generar modelos adecuados para su planificación.

La logística inversa se presenta, básicamente, según cuatro factores [12]:

1. Según la motivación de la reutilización: motivos legales, motivos económicos.

2. Según el tipo de artículo recuperado: embalajes, componentes de repuestos, equipos eléctricos.

3. Según la forma de reutilización: reparación, renovación, reciclaje, reprocesamiento, canibalización $\mathrm{y}$ reutilización.

4. Según los actores implicados: productor, consumidor, reciclador y recogedor.

Como se conoce, el plástico es uno de los elementos más utilizados para el diseño de equipos eléctricos y electrónicos.

En el sector de las tecnologías de la información y telecomunicaciones, el consumo de plástico pasó de 337000 toneladas en 1995 a 595000 toneladas en el año 2000 [13].

Las tecnologías utilizadas para el reciclaje deben garantizar que los residuos puedan separarse en partes individuales.

Por lo tanto, los materiales tóxicos como el plomo en los tubos de rayos catódicos deben ser retirados de los materiales utilizables. La chatarra electrónica contiene principalmente vidrio, plástico $\mathrm{y}$ metal, los cuales se recuperan por procesos de reciclaje, de tal manera que sean vendibles o reutilizables para generar otros productos.

Los programas de electrónica de recolección de residuos residenciales de los EE. UU. muestran que la mayoría de los artículos recopilados consisten en televisores, computadoras y monitores, además de otros aparatos. Metales (49\%), plásticos $(33 \%)$ y tubos de rayos catódicos (12\%) representan más del $90 \%$ de la basura electrónica recolectada. Cuando se recogen solamente los equipos, la distribución es diferente (en peso): vidrio $(25 \%)$, metales $(48 \%)$ y plásticos $(23 \%)$ [14]. Estos resultados muestran que los principales materiales en equipos electrónicos son metales, plásticos y vidrio [13].

Tabla 2. Actividades de la logística inversa. Fuente [12].

\begin{tabular}{cl}
\hline Material & \multicolumn{1}{c}{ Actividades de la logística inversa } \\
\hline & Retorno al proveedor \\
& Reventa \\
& Venta vía fin de existencias \\
Productos & "Caridad» o mercado menos exigente \\
& Reacondicionamiento, renovación o \\
& reprocesamientos por parte de la propia \\
& empresa o por parte de una tercera \\
& Recuperación de materiales \\
& Reciclaje \\
& Vertedero \\
\hline Envases y embalajes & Reutilización \\
& Renovación \\
& Recuperación de materiales \\
& Reciclaje \\
& Caridad \\
\hline
\end{tabular}


Validación de un modelo de logística inversa para la recuperación de los RAEE de la ciudad de Cali, basado en el Pensamiento Sistémico usando una simulación con Dinámica de Sistemas

Una revisión más actualizada de este tema se encuentra en [15], con artículos publicados desde 1992 hasta finales del 2014. El autor logró identificar siete áreas de trabajo frente a los RAEE: i) gestión, ii) generación, iii) caracterización, iv) aspectos sociales, v) reuso o expansión de vida útil, vi) aspectos metodológicos, económicos $\mathrm{y}$ vii) diseño.

Para el reciclaje de RAEE se utilizan cuatro métodos o técnicas:

-Desmontaje y separación manual de los componentes del aparato.

-Reciclaje mecánico, extracción y triturado de materiales.

-Incineración y refinado para la recuperación de metales.

-Reciclaje químico de metales preciosos (oro, plata...) de las placas de circuitos impresos.

Los componentes principales de los RAEE varían significativamente según el tipo de aparato. En la Tabla 3 se detallan los porcentajes de cada componente para algunas de las categorías de RAEE y se identifica que, en electrodomésticos pequeños, equipos informáticos, aparatos para telecomunicaciones, televisores $\mathrm{y}$ radios, el mayor elemento presente en ellos es el plástico.

Cada material recuperado tiene implícito un proceso de revalorización y tratamiento que permite recuperarlo $\mathrm{y}$ devolverlo al ciclo productivo. Estos materiales se clasifican en dos fracciones, los que son valorizables y que se suministran como materias primas a otras industrias y los que no pueden ser utilizados $\mathrm{y}$ deben ser eliminados con tratamientos finales o deben tener una buena disposición de acuerdo con la legislación de cada país.

Se conoce que el comportamiento de los plásticos en los procesos de recuperación es variado y complejo debido a las características que cada uno de ellos posee.

Sin embargo, existen análisis de reciclado conjunto de ABS y HIPS obtenidos de aparatos eléctricos y electrónicos [16] con buenos resultados para la elaboración de plásticos utilizados como materia prima.

La recuperación de estos plásticos se combina con materia prima virgen. Tal combinación logró tener buenos resultados mecánicos después de los ensayos realizados. Esta alternativa es más fácil y económica que la utilizada para hacer la separación con métodos por densidad o la flotación de espuma convencional [12]. Los resultados han sido favorables a pesar de la dificultad presente y el costo económico que acarrea.

Tabla 3. Porcentajes componentes por categoría de RAEE. Fuente: [16].

\begin{tabular}{|c|c|c|c|c|c|}
\hline Categoría de aparato & $\begin{array}{l}\text { Metales } \\
\text { férreos }\end{array}$ & $\begin{array}{l}\text { Metales } \\
\text { no férreos }\end{array}$ & Vidrio & Plástico & Otros \\
\hline Electrodomésticos grandes & $61 \%$ & $7 \%$ & $3 \%$ & $9 \%$ & $21 \%$ \\
\hline Electrodomésticos pequeños & $19 \%$ & $1 \%$ & $0 \%$ & $48 \%$ & $32 \%$ \\
\hline Equipos informáticos & $43 \%$ & $0 \%$ & $4 \%$ & $30 \%$ & $20 \%$ \\
\hline Telecomunicaciones & $13 \%$ & $7 \%$ & $0 \%$ & $74 \%$ & $6 \%$ \\
\hline Televisores, radios, etc. & $11 \%$ & $2 \%$ & $35 \%$ & $31 \%$ & $22 \%$ \\
\hline Lámparas de descarga de gas & $2 \%$ & $2 \%$ & $89 \%$ & $3 \%$ & $3 \%$ \\
\hline
\end{tabular}


Validación de un modelo de logística inversa para la recuperación de los RAEE de la ciudad de Cali, basado en el Pensamiento Sistémico usando una simulación con Dinámica de Sistemas

En el país, la mayor parte de los RAEE que gestiona el sector informal son desensamblados para la comercialización de las partes valiosas con intermediarios y la disposición de las partes inservibles a través de la empresa de aseo local. Los intermediarios, por su parte, se encargan de comprar este material para luego venderlo, ya sea para el aprovechamiento de materiales en empresas nacionales e internacionales de reciclaje o para el aprovechamiento funcional de las partes.

Se constató que lo anterior es una actividad bastante común, pues en cada una de las ciudades estudiadas, se encontró, a nivel informal, un amplio sector dedicado a la reparación de equipos y compraventa de partes funcionales.

Para los televisores, se estima que los residuos a esperar en los cinco años contenidos entre el 2009 y el 2014 se elevarán a aproximadamente en un $240 \%$ frente a los generados en los cinco años anteriores. Del 2009 al 2018, se generarán siete veces más televisores obsoletos que entre el 2004 y el 2008, totalizando 250000 toneladas. A lo largo del período de tiempo entero se suma un volumen de 287000 toneladas. Para los equipos de audio, en su mayor parte formados por radios/equipos de sonido y altavoces, se estimó que del 2004 al 2008 se generaron aproximadamente 42000 toneladas; asimismo, se espera que del 2009 al 2013 y del 2014 al 2018, se generen 71000 toneladas. Las proyecciones para los computadores indican que, para el año 2013, Colombia podía llegar a tener entre 80000 y 140000 toneladas de residuos de este tipo [17].

La tecnología de mayor aplicación para el reciclaje de los residuos de plástico en Colombia es el reciclaje mecánico [18]; con menor importancia, el reciclaje químico y la incineración, esta última empleada principalmente para el reciclaje de empaques y envases plásticos contaminados con productos químicos.
Para el mes de agosto del 2009, el Congreso de Colombia radicó el proyecto Ley 91, "mediante el cual se regula la política pública de residuos de aparatos eléctricos y electrónicos (RAEE) en Colombia". Dicho proyecto describe las responsabilidades y obligaciones de los diferentes actores involucrados en la gestión de los RAEE. Igualmente, en el mismo año fueron radicados los siguientes proyectos de ley: Proyecto Ley 69 de 2009, el cual establece la recompra de pilas, baterías eléctricas y basura electrónica por parte del fabricante, aparte de dictar otras disposiciones, y el Proyecto de Ley 16 de 2009, el cual formula los lineamientos y políticas generales para la implementación de los planes de gestión integral de residuos sólidos "PGRIS" y se establece el reciclaje como instrumento de recursos para todos. El ministerio del Medio Ambiente, Vivienda y Desarrollo Territorial (MAVDT) publicó el proyecto de Resolución n. ${ }^{\circ}$ 4138, "por el cual se establecen obligaciones para la recolección y gestión ambiental de residuos de computadores y periféricos y se adoptan otras disposiciones".

En sistemas complejos como la recuperación del plástico en los RAEE, la dinámica de sistemas permite modelar, de forma natural, comportamientos a través de interacciones entre los procesos por medio de bucles de retroalimentación positivos y negativos, análisis de relaciones por lo general no lineales y la posibilidad de hacer estudios frente aspectos cualitativos presentes en un determinado contexto.

Una de las primeras aproximaciones en la literatura, desde la dinámica de sistemas a la gestión de residuos sólidos, fue la desarrollada por [19]. El autor presentó un modelo de dinámica de sistemas para analizar la gestión de residuos sólidos en el estado de Nueva York. El modelo relaciona la interacción entre la generación de residuos sólidos, la respuesta de los entes gubernamentales 
Validación de un modelo de logística inversa para la recuperación de los RAEE de la ciudad de Cali, basado en el Pensamiento Sistémico usando una simulación con Dinámica de Sistemas

para su tratamiento, el presupuesto, el reciclaje ilegal, los diferentes métodos de tratamiento de los residuos y los efectos ambientales del sistema. Los resultados de la simulación sugieren que la estructura del sistema propicia una transición desde la disposición de residuos sólidos en vertederos a un mayor aprovechamiento de otras alternativas como el reciclaje y la incineración. Esta transición demanda una gran inversión de recursos de capital por parte de las entidades gubernamentales.

Frente a este hecho, la simulación sugiere que, de no realizarse de manera efectiva estas inversiones, se propiciaría el reciclaje ilegal, escenario que a largo plazo es más costoso que la inversión de corto plazo demandada por el sistema.

Posteriormente, utilizaron dinámica de sistemas para modelar la Gestión de Residuos Sólidos Urbanos (USWM) generados por los hogares de países en desarrollo como la India [20]. Lo que buscaba el modelo era cuantificar los aspectos cualitativos modelando la relación entre la recogida de residuos formales, reciclaje informal y el sistema de generación de residuos de países en desarrollo. Esto debe suceder a medida que el sistema responde a los cambios en el medio ambiente, teniendo en cuenta aspectos de salud, medio ambiente, costo presente y futuro de la sociedad, y los aspectos sociales.

Otro enfoque de simulación para el tema, aunque no es basado en simulación con dinámica de sistemas, es el planteado para el desarrollo del modelo ORWARE (Residuos Orgánicos de Investigación) [21].

Este es un modelo desarrollado principalmente como una herramienta para los investigadores en el análisis de sistemas de gestión de residuos del medio ambiente, basado en un computador que calcula los flujos de sustancias, el impacto ambiental y los costos de la gestión de residuos. El modelo cubre, a pesar del nombre, tanto residuos municipales orgánicos como fracciones inorgánicas. Los submodelos se pueden combinar para diseñar un sistema completo de gestión de residuos dado en la práctica.

Posteriormente, se desarrollaron otros modelos desde la dinámica de sistemas, como un modelo que trató de representar los principales factores responsables de la degradación del medio ambiente en las cuencas y la contaminación de las aguas de la Bahía de Sepetiba [22]. Los resultados de la simulación proponen llegar al objetivo medioambiental a través de diferentes estrategias de asignación de recursos, que son distintas tanto espacial como temporalmente.

Por otra parte, acerca del impacto de la generación de residuos en la ciudad de Newark, USA, [23] proporcionó información valiosa sobre el proceso de gestión de los residuos sólidos urbanos. Los resultados mostraron que los residuos aumentan de forma general durante el período de pronóstico, debido al incremento en las dimensiones de la población y variaciones socioeconómicas. Asimismo, muestra la capacidad de los vertederos existentes permitida para ser utilizados por completo en un lapso de nueve años (en 2012).

El estudio reveló, además, que, si el reciclaje se cobrara, esto generaría un impacto adverso, ya que el número de vertederos aumentaría. Por ello, se recomiendan nuevas medidas políticas que reduzcan el costo de reciclaje, además de aumentar los mercados para los materiales reciclables.

En la búsqueda de mejoras operativas para el reciclaje, se desarrolla un modelo con dinámica de sistemas para analizar el flujo de materiales y el rendimiento de reciclaje para diferentes tipos de residuos, especialmente RAEE, que están vinculados al desempeño de la liberación y la separación de reciclaje [24].

\section{METODOLOGíA}

En [25] se inició el campo de investigación de la dinámica de sistemas, un enfoque de simulación computacional 
Validación de un modelo de logística inversa para la recuperación de los RAEE de la ciudad de Cali, basado en el Pensamiento Sistémico usando una simulación con Dinámica de Sistemas

para el análisis y diseño de políticas a partir de la evaluación de sus efectos en un sistema bajo estudio.

Conceptualmente, la teoría general de sistemas y de realimentación 0 pensamiento en bucles es el centro de la dinámica de sistemas. Los diagramas de influencias o causalidad son el enfoque conceptual utilizado por esta técnica para representar la estructura de sistemas complejos. Luego, esta representación cualitativa es traducida al modelo matemático, que, al solucionarse, brinda la historia artificial o el comportamiento que emerge de la estructura del sistema.

Matemáticamente, la estructura básica de un modelo de simulación de dinámica de sistemas es un conjunto de ecuaciones no lineales, diferenciales o integrales de primer orden.

Estas características hacen necesaria la aplicación de metodologías distintas de otras técnicas como la simulación discreta.

Asimismo, son diferentes las maneras de estructurar y analizar los datos de entrada y salida de estos modelos. En la literatura se evidencia el proceso de modelación con dinámica de sistemas [26], [27], [28], [29].

La metodología de la modelación con dinámica de sistemas sigue, de manera general, unos lineamientos establecidos por [25]. Esta consta de dos grandes fases, una cualitativa, aplicada desde la perspectiva del pensamiento sistémico, y otra cuantitativa, denominada en la literatura como dinámica de sistemas.

Siguiendo el esquema propuesto por [25], se presenta entonces el siguiente desarrollo para construcción del modelo de dinámica de sistemas:

-Construcción del modelo cualitativo

-Formulación del modelo matemático

-Simulación con dinámica de sistemas.

El desarrollo del modelo se basó en la revisión de la literatura, en la que se encontraron modelos teóricos de logística inversa [12] y trabajos que ya han utilizado la dinámica de sistemas como herramienta para abordar el problema de investigación de este estudio [24] o que tienen estrecha relación con la gestión ambiental y de residuos [19], [20], [21] y [23]. Además de esta base teórica, se involucró en este diseño la participación de expertos de una empresa de recuperación de plásticos de la ciudad de Cali.

\subsection{Supuestos del modelo}

El diseño propuesto se basa en las condiciones presentes en la región y es una opción para alcanzar el diseño de un sistema de gestión integral; en el modelo se identificaron los principales elementos de interés del sistema detallados en los gráficos. En ellos, se representan cualitativamente los elementos estrechamente relacionados con la logística estudiada, a saber: demandas, inventarios, medios de recolección, ciclo de vida de productos, utilidad de venta de pellet, utilidad de productos recuperados y el esquema de control de producción para los procesos de aprovechamiento. A su vez, se establecen las relaciones entre estos elementos y el sentido de estas (directa, polaridad positiva, o indirecta, polaridad negativa). Los elementos resaltados en rojo en los diagramas son parámetros, es decir, una entrada para el modelo.

El esquema de producción modelado fue establecido por los expertos como un esquema por orden de producción, debido a la alta variabilidad e incertidumbre en la oferta de RAEE para recuperar, así como de las condiciones de demanda para productos recuperados, o venta directa de Pellet recuperado.

Un primer bucle identificado en este análisis es la relación entre las ventas de AEE y la demanda del mismo (Fig. 4). Como se mencionó antes, el mercado en Colombia de los Aparatos Eléctricos y Electrónicos (AEE) se encuentra en crecimiento, lo que se representa en un bucle de refuerzo que indica que, a más ventas de $\mathrm{AEE}$, la demanda crece y esta a su vez refuerza las 
Validación de un modelo de logística inversa para la recuperación de los RAEE de la ciudad de Cali, basado en el Pensamiento Sistémico usando una simulación con Dinámica de Sistemas

ventas. Este bucle, el único de refuerzo identificado, es el que impulsa toda la dinámica del sistema de logística inversa representado en el diagrama de influencias. El efecto de este bucle en el tiempo es un aumento constante en la generación de RAEE y con esto un aumento en el nivel de los mismos.

Dada esta generación, el primer eslabón del modelo teórico propuesto por [12] toma lugar, es decir, el proceso de recolección.

En este proceso se modelan los actores propios del contexto colombiano, la recolección informal, la recolección propia y la subcontratada con terceros. Estos elementos conforman bucles de compensación, estructura del modelo que se contrapone al efecto de refuerzo entre las ventas de AEE y la demanda de los mismos. Esto quiere decir que un aumento constante de los RAEE se verá mitigado por todos los actores de recolección que ya están establecidos; asimismo, una disminución abrupta en la demanda de AEE y generación de RAEE puede provocar una contracción en el nivel de recolección.

Los siguientes eslabones del modelo de logística inversa son establecidos para un proceso de recuperación de plástico como se nota en la Fig. 5. Las características de este material permiten establecer un proceso estándar de: i) selección, en el que se separa de manera manual los RAEE que pueden ingresar al proceso, ii) separado, en el que se separa el material plástico a recuperar, tomando en cuenta el tipo de plástico, iii) molido, en el que se muele de manera inicial el material, iv) lavado, en el que se limpian impurezas del material molido, v) remolido, segunda secuencia de molido del material, vi) secado $\mathrm{y}$ finalmente, vii) pelletizado, en el que se elabora el pellet de plástico recuperado, material que puede venderse directamente o ser usado para fabricar otros productos.

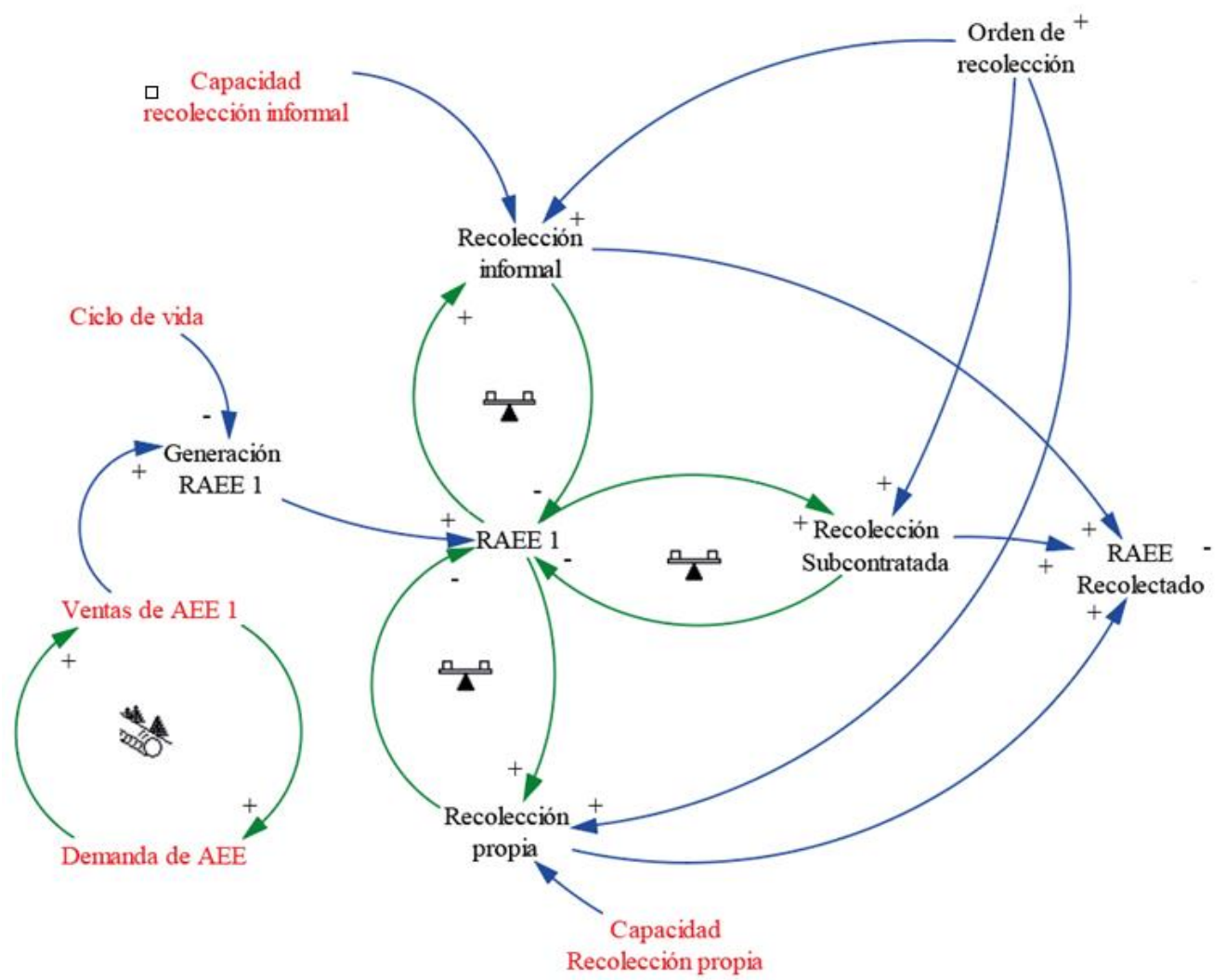

Fig. 4. Diagrama de influencias, generación de RAEE. Fuente: elaboración propia. 
Validación de un modelo de logística inversa para la recuperación de los RAEE de la ciudad de Cali, basado en el Pensamiento Sistémico usando una simulación con Dinámica de Sistemas

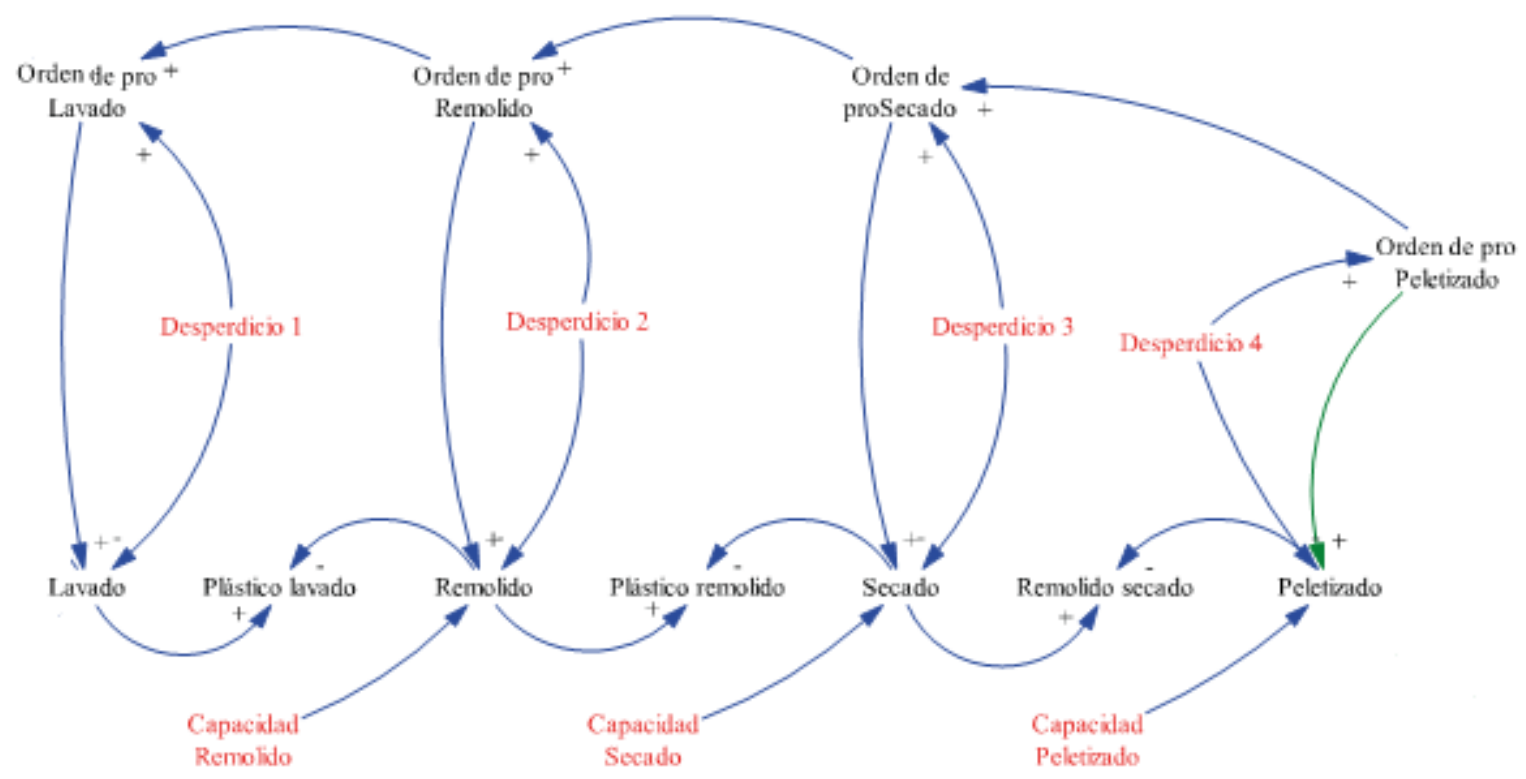

Fig. 5. Diagrama de influencias, procesos de recuperación. Fuente: elaboración propia.

La última sección del sistema corresponde a la conexión entre el sistema de producción y los elementos de demanda, inventario de pellet, producción de pellet recuperado (en el diagrama "Pelletizado").

Además, se incluye la consideración de dos posibles destinos para el proceso de recuperación.

El primero corresponde a la venta directa del pellet recuperado, el segundo, considera la posibilidad de elaborar productos a partir del pellet recuperado.

Se modela entonces la preferencia entre una u otra de estas opciones mediante una comparación directa de las utilidades de estas dos alternativas, lo que implicó la inclusión del elemento "Asignación de pellet a producción". Como se aprecia en la Fig. 6, cuanto más se asigne pellet a producción, más producción de productos recuperados se obtiene; por el contrario, cuanto más se asigne pellet a producción, menos ventas de pellet recuperado se van a obtener (ya que el pellet se utiliza para producción).

Esta sección del sistema cuenta con un bucle de compensación entre los elementos "Orden de pro Pelletizado", "Pelletizado", "Pellet Recuperado" y "Brechas de producción Pellet”. Como se observa en el modelo propuesto, las demandas se relacionan directamente con las ventas, y estas ventas se relacionan negativamente con los niveles de inventario de "Pellet Recuperado" y "Productos Recuperados".

Es decir, en neto, un aumento de las ventas disminuye los inventarios finales del sistema. Cuando se afecta negativamente el bucle de compensación, se provoca una reacción del sistema que tiende a aumentar los elementos del bucle, como la orden de producción de pelletizado, y con esta el inventario de pellet ("Pellet Recuperado"). De todas formas, estos efectos están sujetos a otros elementos restrictivos del sistema como las capacidades de producción o disponibilidades de AEE.

Finalmente, el modelo diseñado en el diagrama de influencias se traduce al diagrama de Forrester (Fig. 7). En este diagrama, se identifican las variables de nivel, flujo, auxiliares y parámetros del sistema (parámetros resaltados en rojo).

Esta versión se asemeja al diagrama de influencias, pero cuenta con un diseño adaptado a la simulación. 
Validación de un modelo de logística inversa para la recuperación de los RAEE de la ciudad de Cali, basado en el Pensamiento Sistémico usando una simulación con Dinámica de Sistemas

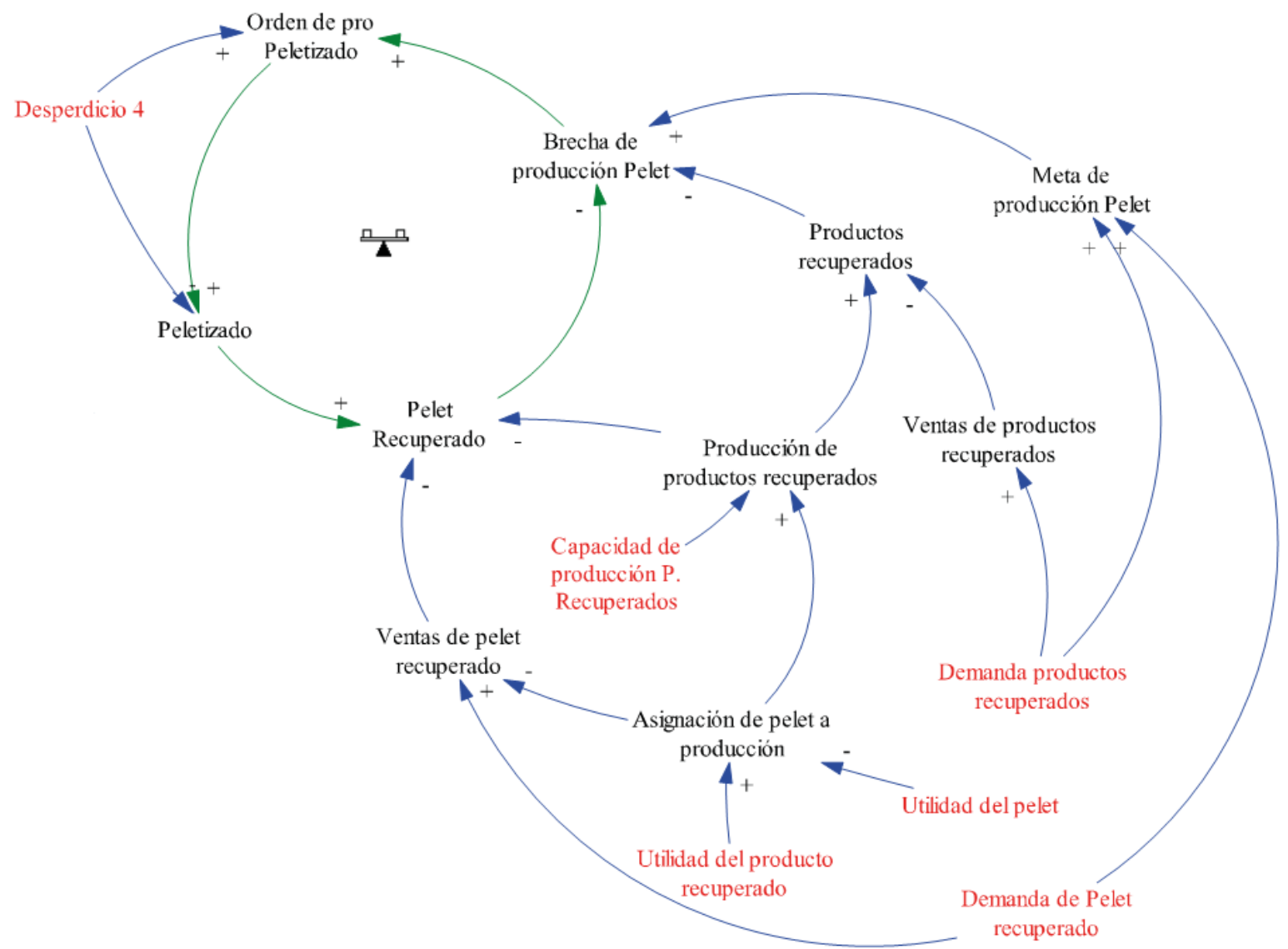

Fig. 6. Diagrama de influencias, venta de pellet y productos recuperados

Fuente: elaboración propia.

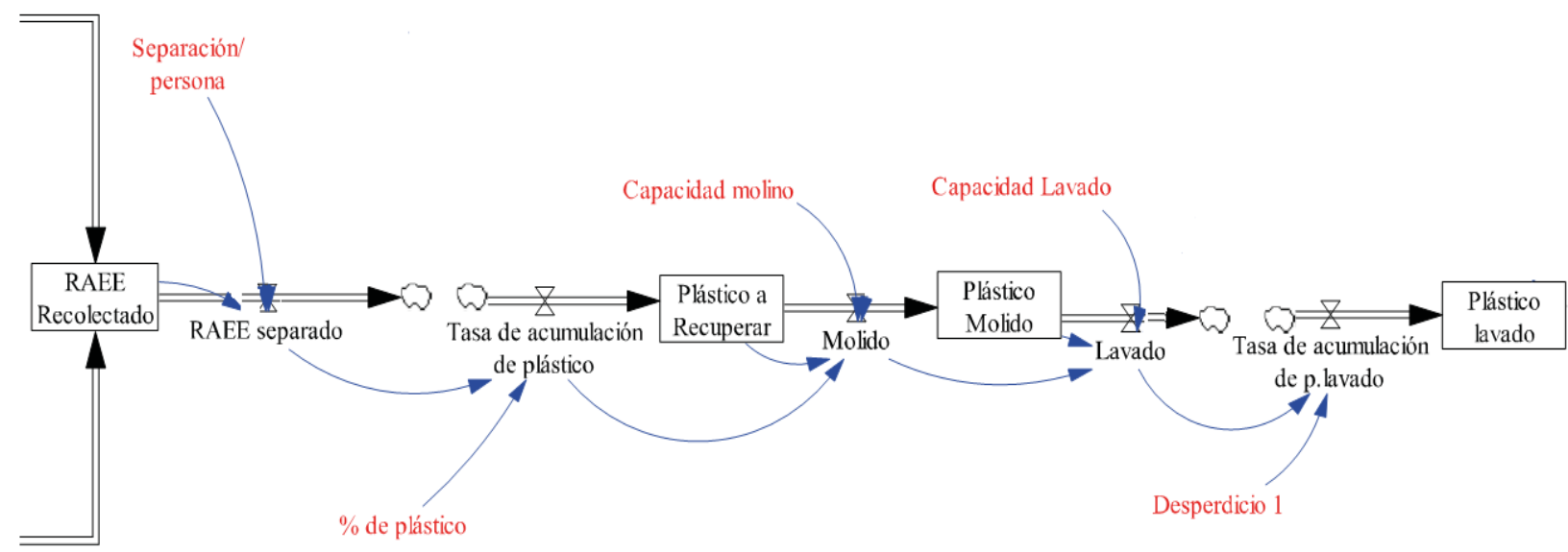

Fig. 7. Diagrama de Forrester, venta de pellet y productos recuperados

Fuente: elaboración propia. 
Validación de un modelo de logística inversa para la recuperación de los RAEE de la ciudad de Cali, basado en el Pensamiento Sistémico usando una simulación con Dinámica de Sistemas

\subsection{Notación y definición}

\section{Variables de nivel}

RAEE:

RAEE recolectado:

Plástico molido:

Plástico lavado:

Plástico remolido:

Remolido secado:

Plástico lavado:

Pellet recuperado:

Productos recuperados:

\section{Variables de flujo}

Generación de RAEE:

Recolección informal:

Recolección subcontratada:

Recolección propia:

RAEE separado:

Tasa de acumulación de plástico:

Molido:

Lavado:

Tasa de acumulación de $\mathrm{p}$. lavado:

Remolido:

Tasa de acumulación de $\mathrm{p}$. remolido:

Secado:

Tasa de acumulación de p. secado:

Pelletizado: tasa de acumulación de p. pelletizado:
Representa la cantidad de residuos de aparatos eléctricos y electrónicos en el periodo.

Representa la acumulación de residuos de aparatos eléctricos y electrónicos recolectados en el período.

Cantidad de plástico molido durante el periodo.

Cantidad de plástico lavado en el periodo.

Cantidad de plástico remolido en el periodo.

Cantidad de plástico remolido en el proceso de secado durante el periodo.

Cantidad de plástico lavado durante el periodo.

Cantidad de plástico en pellet ya recuperados durante el periodo.

Cantidad de productos recuperados en el periodo.
Tasa de generación de residuos de aparatos eléctricos y electrónicos en el periodo.

Tasa de recolección de residuos de aparatos eléctricos y electrónicos del sector informal durante el período.

Tasa de recolección de residuos de aparatos eléctricos y electrónicos subcontratada por la empresa durante el período.

Tasa de recolección de residuos de aparatos eléctricos y electrónicos realizada por la empresa en el período.

Tasa de residuos de aparatos eléctricos y electrónicos separado en el período.

Tasa de plástico acumulado en el periodo para iniciar proceso de recuperación.

Tasa de plástico molido en el período.

Tasa de plástico lavado en el período.

Tasa de plástico lavado acumulado durante el periodo.

Tasa de plástico remolido en el proceso durante el periodo.

Tasa de plástico remolido acumulado durante el periodo.

Tasa de plástico secado en el proceso durante el periodo.

Tasa de plástico secado acumulado durante el periodo.

Tasa de plástico pelletizado en el proceso durante el periodo.

Tasa de plástico acumulado en el proceso de pelletizado durante el periodo. 
Validación de un modelo de logística inversa para la recuperación de los RAEE de la ciudad de Cali, basado en el Pensamiento Sistémico usando una simulación con Dinámica de Sistemas

producción de productos

recuperados:

ventas de productos

recuperados:
Tasa de producción de productos recuperados durante el periodo.

Tasa de ventas de productos recuperados durante el periodo.

ventas de pellet recuperado: Tasa de ventas de pellet recuperado durante el periodo.

Número de órdenes de producción en cada una de las estaciones del proceso durante el periodo. Las variables auxiliares que representan esta característica en cada uno de los procesos son:

- Orden de recolección

- Orden pro.separado

- Orden pro.molido

- Orden pro.lavado

- Orden pro.remolido

- Orden pro.secado

- Orden pro.pelletizado

Brecha de producción pellet:

Meta de producción:

Comparación producto vs pellet:
Diferencia que existe entre el número de unidades a producir de pellet y la cantidad de inventario que se tiene para el período.

Sumatoria de unidades a producir a partir de la demanda de productos recuperados y la demanda de pellet recuperado para el período.

Variable que compara la utilidad del pellet y el producto recuperado en el período.

\section{Parámetros}

\section{Parámetro}

$\%$ de plástico

$\%$ recolección informal

\% recolección propia

$\%$ recolección subcontratada

Capacidad lavado

Capacidad molino

Capacidad pelletizado

Capacidad producción pr

Capacidad recolección informal

Capacidad recolección propia

Capacidad remolido

Capacidad secado

Peso de AEE

Demanda de pellet recuperado-Dis. triangular

\section{Datos}

$30 \%$
$6 \%$
$40 \%$
$20 \%$
$7 \mathrm{Tn}$
$8 \mathrm{Tn}$
$6 \mathrm{Tn}$
$5 \mathrm{Tn}$
$5 \mathrm{Tn}$
$20 \mathrm{Tn}$
$5 \mathrm{Tn}$
$7 \mathrm{Tn}$
$15 \mathrm{Kg}$

(Min 2, Esp 3, Max 4) 
Validación de un modelo de logística inversa para la recuperación de los RAEE de la ciudad de Cali, basado en el Pensamiento Sistémico usando una simulación con Dinámica de Sistemas

Demanda de productos recuperados Dis. triangular

Desperdicio 1 (Cap.lavado)

Desperdicio 2 (Cap.remolido)

Desperdicio 3 (Cap.secado)

Desperdicio 4 (Cap.pelletizado)

Utilidad producto recuperado

Separación/persona

Utilidad del pellet

Ventas de AEE
(Min 4, Esp 6, Max 7)

$5 \%$

$3 \%$

$3 \%$

$5 \%$

$$
\$ 3500000 / \mathrm{Tn}
$$

$2 \mathrm{Tn}$

$\$ 2000000 / \mathrm{Tn}$

2305 unidades/día

\subsection{Formulación matemática}

Brecha de producción pellet $=$ Max (Meta de producción $-($ Pellet Recuperado + Productos recuperados $)$, o $)$

Comparación Producto vs pellet = IF THEN ELSE $($ PV de producto recuperado > Utilidad del pellet, 1, 0 )

Generación RAEE $=$ Ventas de AEE * Peso de AEE

Ingreso por productos recuperados $=\mathrm{PV}$ de producto recuperado * Ventas de productos recuperados

Ingreso por venta de pellet $=$ Utilidad del pellet * Ventas de Pellet Recuperado

Lavado = MIN (MIN (Orden de pro. Lavado, Plástico Molido + Molido), Capacidad Lavado)

Meta de producción $=$ Demanda de pellet recuperado + Demanda de productos recuperados

Molido = MIN (MIN (Plástico a Recuperar + Tasa de acumulación de plástico, Orden de pro. Molido)

,Capacidad molino)

Orden de pro. Lavado $=($ Orden de pro. Remolido $/(1-$ Desperdicio 1$))$

Orden de pro. Molido = Orden de pro. Lavado

Orden de pro. Pelletizado $=\operatorname{MAX}(0,($ Brecha de producción pellet $/(1$-Desperdicio 4$))$

Orden de pro. Remolido $=($ Orden de pro. Secado $/(1$-Desperdicio 2$))$

Orden de pro. Secado $=($ Orden de pro. Pelletizado $/(1$-Desperdicio 3$))$

Orden de pro. Separado = Orden de pro. Molido $/ \%$ de plástico

Orden de Recolección = Orden de pro. Separado

Pellet Recuperado = INTEG(Tasa de acumulación de p.pelletizado - Producción de productos recuperados-

Ventas de Pellet Recuperado,30)

Pelletizado = MIN (MIN (Tasa de acumulación de p.secado + Remolido secado, Orden de pro. Pelletizado) ,

Capacidad Pelletizado)

Personal asignado $=$ Orden de pro. Separado/Separación/persona

Plástico a Recuperar = INTEG $($ Tasa de acumulación de plástico - Molido,0)

Plástico lavado = INTEG $($ Tasa de acumulación de p.lavado - Remolido,0)

Plástico Molido = INTEG (Molido - Lavado,0)

Plástico remolido = INTEG (Tasa de acumulación de p.remolido - Secado,0)

Producción de productos recuperados $=$ Comparación Producto vs pellet * MIN(MIN( Demanda de productos recuperados, Pellet Recuperado + Tasa de acumulación de p.pelletizado), Capacidad producción pr)

Productos recuperados = INTEG $($ Producción de productos recuperados - Ventas de productos recuperados,0)

RAEE = INTEG (Generación RAEE - Recolección informal - Recolección Propia-Recolección subcontratada,0) RAEE Recolectado = INTEG (Recolección informal + Recolección Propia + Recolección subcontratada - RAEE separado,0)

[72] TecnoLógicas, ISSN-p 0123-7799 / ISSN-e 2256-5337, Vol. 23, No. 48, mayo-agosto de 2020, pp. 55-81 
Validación de un modelo de logística inversa para la recuperación de los RAEE de la ciudad de Cali, basado en el Pensamiento Sistémico usando una simulación con Dinámica de Sistemas

RAEE separado = MIN (Separación/persona * Personal asignado, MIN (Orden de pro. Separado, RAEE

Recolectado + Recolección informal + Recolección Propia + Recolección subcontratada))

Recolección informal = MIN (MIN(Orden de Recolección * \% recolección informal, Capacidad Recolección informal $),($ RAEE + Generación RAEE $)$ \% recolección informal)

Recolección Propia $=$ MIN $($ (RAEE + Generación RAEE $)$ \% recolección propia, MIN(Orden de Recolección *

\% recolección propia , Capacidad Recolección propia))

Recolección subcontratada $=$ MIN(Orden de Recolección * \% recolección subcontratada, (RAEE +

Generación RAEE) * \% recolección subcontratada)

Remolido = MIN (MIN (Orden de pro. Remolido, Plástico lavado + Tasa de acumulación de p.lavado) ,

Capacidad Remolido)

Remolido secado = INTEG (Tasa de acumulación de p.secado-Pelletizado,0)

Secado = MIN (MIN (Orden de pro. Secado , Plástico remolido + Tasa de acumulación de p.remolido) ,

Capacidad Secado)

Tasa de acumulación de p.lavado = Lavado * (1 - Desperdicio 1)

Tasa de acumulación de p.pelletizado $=$ Pelletizado * $(1-$ Desperdicio 4$)$

Tasa de acumulación de p.remolido $=$ Remolido * $(1-$ Desperdicio 2$)$

Tasa de acumulación de p.secado $=$ Secado * $(1-$ Desperdicio 3$)$

Tasa de acumulación de plástico = RAEE separado * \% de plástico

\section{RESULTADOS Y DISCUSIÓN}

En la actualidad, los datos disponibles sobre los desechos eléctricos y electrónicos son pobres e insuficientes y se requieren técnicas de estimación para la extensión de los datos conocidos a una cobertura regional y mundial.

En primer lugar, se hicieron visitas a los centros y empresas donde se acopian los residuos de aparatos eléctricos $\mathrm{y}$ electrónicos formales e informales. Aunque se lograron identificar procesos propios de esta industria emergente, no se encontraron respuestas efectivas sobre la cantidad de toneladas que resultan en un periodo determinado de este tipo de residuos.

Con respecto a las empresas de Lito y Datecsa S. A., se logró tener contacto con la segunda. Datecsa informó que recolecta aproximadamente entre 25 y 30 toneladas mensuales de equipos obsoletos, obtenidos por reposición de equipos eléctricos $\mathrm{y}$ electrónicos cuando el cliente compra un aparato nuevo.

De la empresa Lito no fue posible obtener información, pues esta no facilita el ingreso y acceso a sus instalaciones para recopilar información sobre el tema de recuperación y sobre los procesos que adelantan.

Dadas estas condiciones, para el estudio se seleccionaron los RAEE generados por el mercado de informática y las telecomunicaciones (esto incluye: computadores personales de escritorio, proyecciones de generación incluyendo CPU, ratón, pantalla y teclado, (Tabla 4); asimismo, se estimó la generación de este tipo de RAEE para la ciudad de Cali. Para determinar la generación de RAEE, todos los datos de entrada para la simulación se consignan en la sección de parámetros, discutida anteriormente. Las distribuciones de demanda se determinaron a partir de distribuciones triangulares dadas por los expertos, debido a la inexistencia de datos históricos para hacer ajustes de distribución.

Las variables de interés desde la perspectiva de la logística implicada son el comportamiento de los niveles de inventario a lo largo de todos los procesos, los niveles de recolección y procesamiento. 
Validación de un modelo de logística inversa para la recuperación de los RAEE de la ciudad de Cali, basado en el Pensamiento Sistémico usando una simulación con Dinámica de Sistemas

Tabla 4. Proyección de ventas de computadores en Cali Fuente: [30].

\begin{tabular}{ccc}
\hline Año & Computadores & Promedio \\
\hline 2003 & 35000000 & 972.22 \\
2004 & 31000000 & 861.11 \\
2005 & 43000000 & 1194.44 \\
2006 & 46000000 & 1277.78 \\
2007 & 65000000 & 1805.56 \\
2008 & 70000000 & 1944.44 \\
2009 & 730000.00 & 2027.78 \\
2010 & 800000.00 & 2222.22 \\
2011 & 830000.00 & 2305.56 \\
2012 & 950000.00 & 2638.89 \\
2013 & 1100000.00 & 3055.56 \\
2014 & 1250000.00 & 3472.22 \\
2015 & 1300000.00 & 3611.11 \\
2016 & 1350000.00 & 3750.00
\end{tabular}

Lo anterior está sujeto a los parámetros exógenos al modelo de capacidades, demandas, niveles de desperdicio, asignación de canales de recolección y preferencia de ventas (entre venta de pellet o productos recuperados).

La simulación se hizo para un periodo de 24 días, lo correspondiente a un mes de trabajo. Se desarrollaron dos simulaciones, la primera con todos los datos descritos y otra con una disminución en el valor esperado, máximo y mínimo de la demanda de productos recuperados (parámetros: Min. 3, Esp. 4 y Máx. 5).

El primer elemento de análisis es el comportamiento de los RAEE. Como se explicó en el modelo cualitativo, actualmente la tendencia de las ventas de los AEE está en constante crecimiento, lo que aumenta a su vez la generación de RAEE.

Como se observa en la Fig. 8, las dos simulaciones que se hicieron al modelo para la recolección de RAEE bajo el esquema de fabricación por orden de producción están sujetas al comportamiento de la demanda de pellet y productos recuperados. La primera simulación a) y la segunda simulación b) presentan el comportamiento de la demanda para la recolección informal.

De esta manera: línea azul: la recolección subcontratada, línea roja: la recolección propia, línea verde: el total de RAEE recolectado, línea gris y el total de RAEE separado: línea negra.

Una característica del modelo es que tiene en cuenta desde las relaciones, desperdicios y el porcentaje de plásticos presentes en los RAEE estudiados desde la venta, hasta todos los procesos productivos, para determinar las toneladas de RAEE necesarias. De igual forma, se observan de manera discriminada los distintos canales de recolección seleccionados.

Esta característica permite separar los volúmenes de cada canal de recolección, lo que permitiría evaluar, con datos de costos múltiples, propuestas en esta configuración. 
Validación de un modelo de logística inversa para la recuperación de los RAEE de la ciudad de Cali, basado en el Pensamiento Sistémico usando una simulación con Dinámica de Sistemas

RAEE

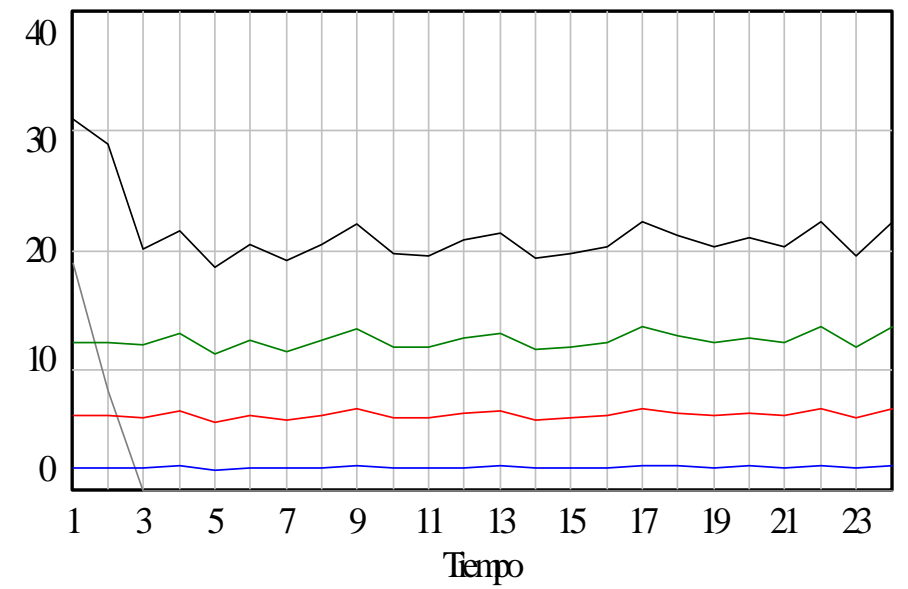

a)

\section{RAEE}

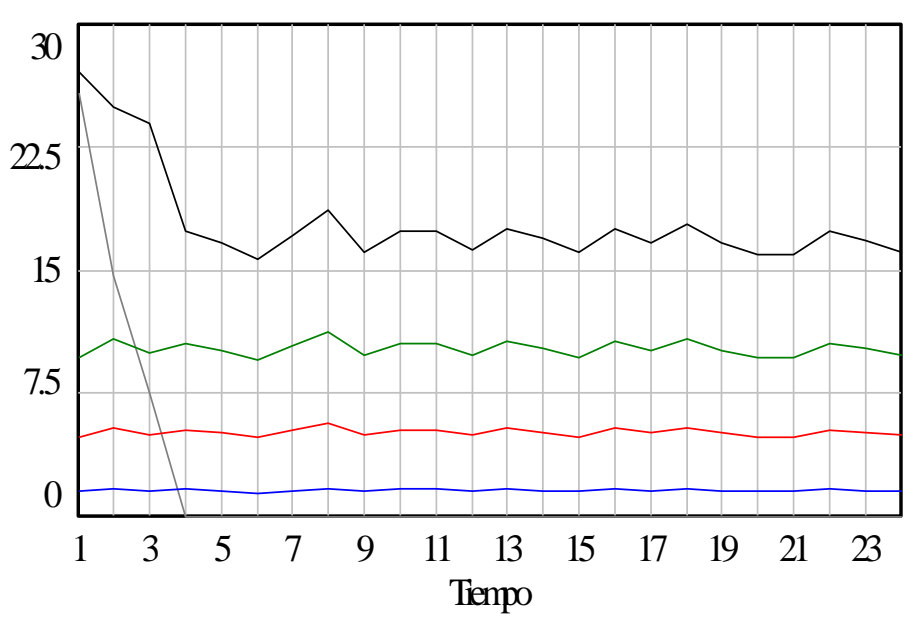

b)

Fig. 8. Resultados, inventario y recolección de RAEE. Fuente: elaboración propia.

Por otro lado, el modelo representa de manera correcta la disyuntiva propia de esta industria entre vender pellet 0 producir productos recuperados. Estos comportamientos se observan con detalle en la Fig. 9.

En la simulación 1 a), la demanda de productos recuperados en el tiempo (línea negra) es superior a la capacidad productiva del sistema (línea azul); bajo este escenario, y teniendo en cuenta que la fabricación propia de productos recuperados brinda una mayor utilidad, las ventas de productos recuperados se mantienen constantes (a lo máximo que puede producir el sistema), mientras que las ventas de pellet son nulas.

En cambio, en la simulación 2 b), en la que la demanda de productos recuperados se ve afectada, se presentan momentos en el tiempo en que esta demanda es cubierta por la capacidad productiva del sistema; cuando esto ocurre, se opta por vender el pellet recuperado. 
Validación de un modelo de logística inversa para la recuperación de los RAEE de la ciudad de Cali, basado en el Pensamiento Sistémico usando una simulación con Dinámica de Sistemas

\section{Producto Terminado}

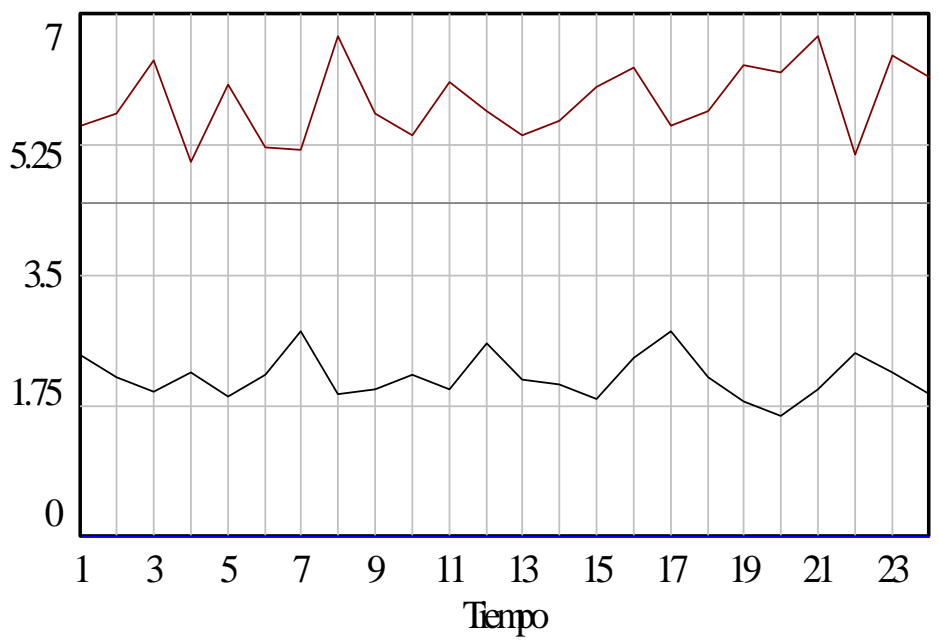

a)

\section{Producto Terminado}

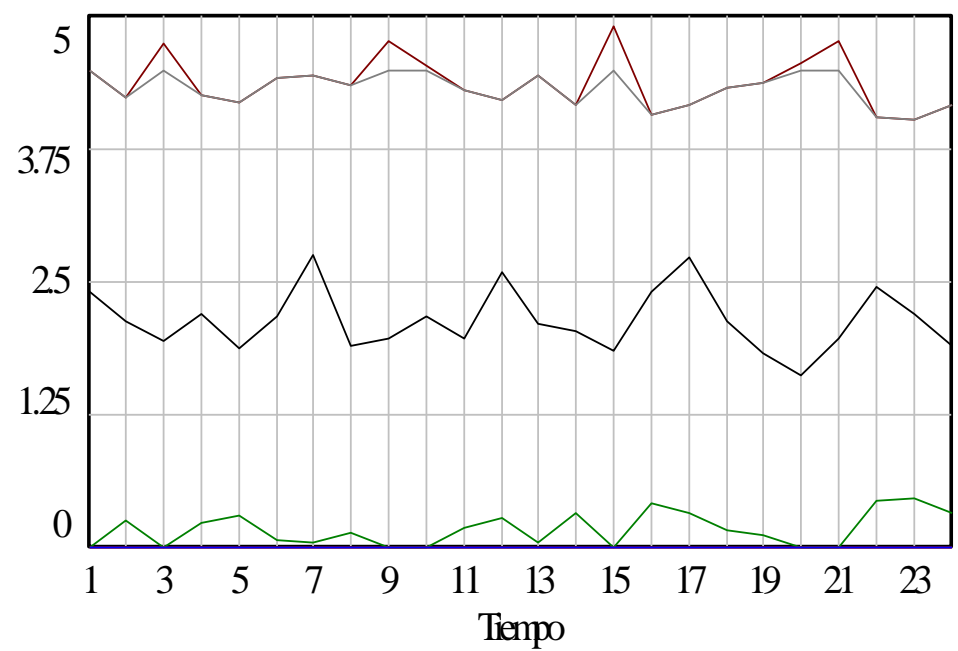

b)

Fig. 9. Resultados, producto terminado, demanda y ventas. Fuente: elaboración propia.

Todos estos comportamientos estiman en su formulación matemática las limitaciones de capacidad, el inventario, la demanda y sus relaciones para determinar de manera correcta las ventas.

De igual manera, puede observarse el comportamiento de los inventarios en proceso. En la Fig. 10 en a) se ven los inventarios en proceso al terminar una unidad de tiempo de simulación, es decir, un día laboral. Solo se presentan inventarios en proceso de plástico molido, a recuperar y lavado b) (línea roja, línea azul, línea verde respectivamente). Estos inventarios se ocasionan por las diferencias en las capacidades de cada uno de los procesos productivos. Los procesos con suficiente capacidad se ven igualados a 0 .

Todo este comportamiento es natural, dada la estructura planteada en el modelo en el que la orden de producción solo está determinada a partir de la necesidad de producción y los desperdicios generados entre un proceso y otro. 
Validación de un modelo de logística inversa para la recuperación de los RAEE de la ciudad de Cali, basado en el Pensamiento Sistémico usando una simulación con Dinámica de Sistemas

\section{Productoen Proceso}

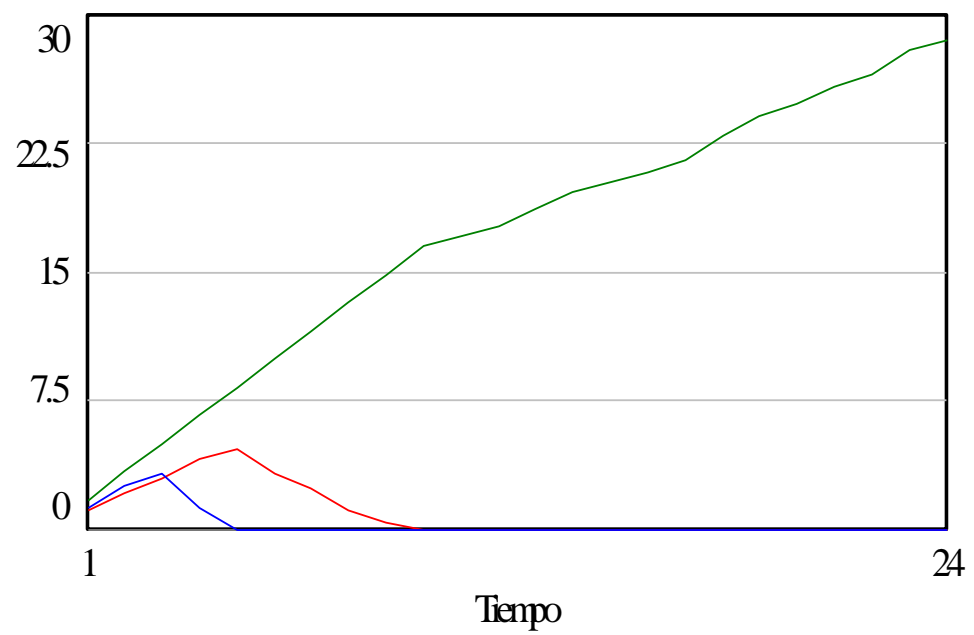

a)

ProductoenProceso

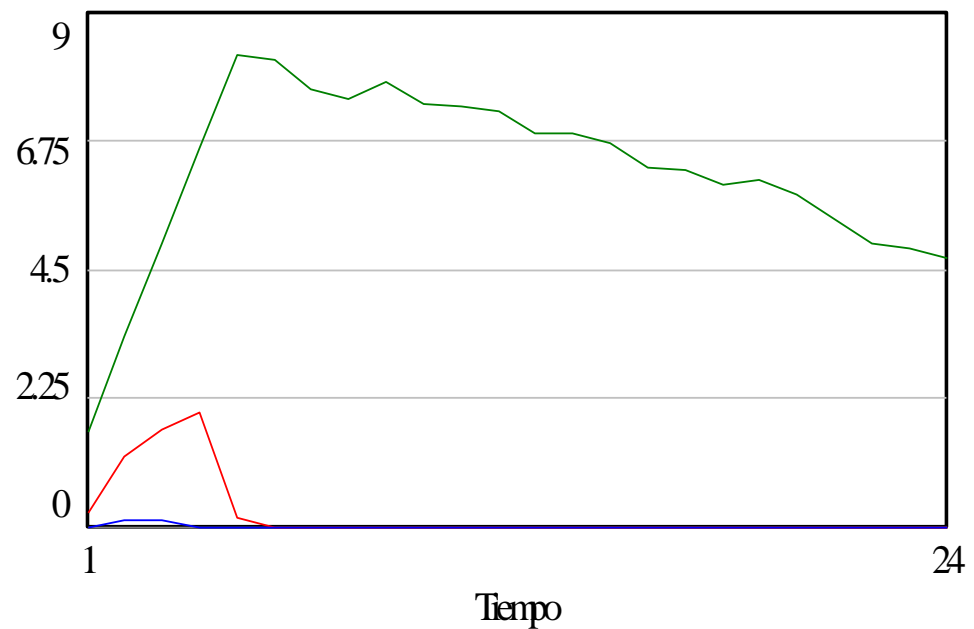

b)

Fig. 10. Resultados, producto en proceso. Fuente: elaboración propia.

Bajo este esquema, el comportamiento de los resultados sugiere que el modelo representa adecuadamente la estructura propuesta, ya que se esperaría un aumento en el producto en proceso, aguas arriba de los procesos cuello de botella.

Otro aspecto para analizar es el comportamiento de los niveles de producción (Fig. 11). Esto permite identificar dos procesos que operan a capacidad máxima (secado y remolido, líneas azul y rojo respectivamente) en a) y b).

Igualmente, la producción de los otros procesos se determina a partir de las necesidades provocadas por los niveles de servicio, por lo que siguen el mismo comportamiento. 
Validación de un modelo de logística inversa para la recuperación de los RAEE de la ciudad de Cali, basado en el Pensamiento Sistémico usando una simulación con Dinámica de Sistemas

\section{Producción}

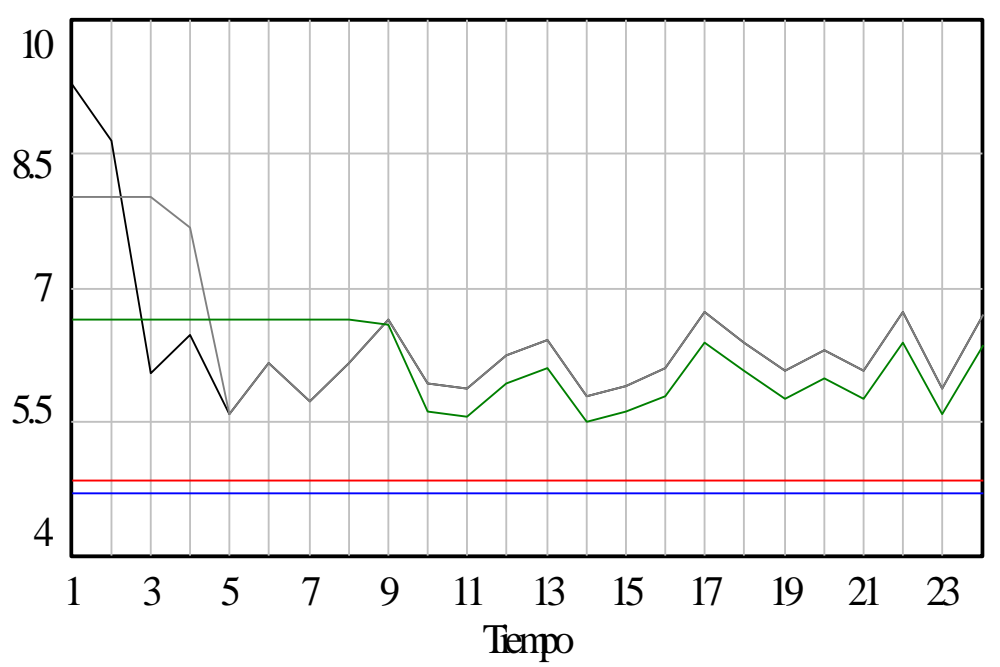

a)

\section{Producción}

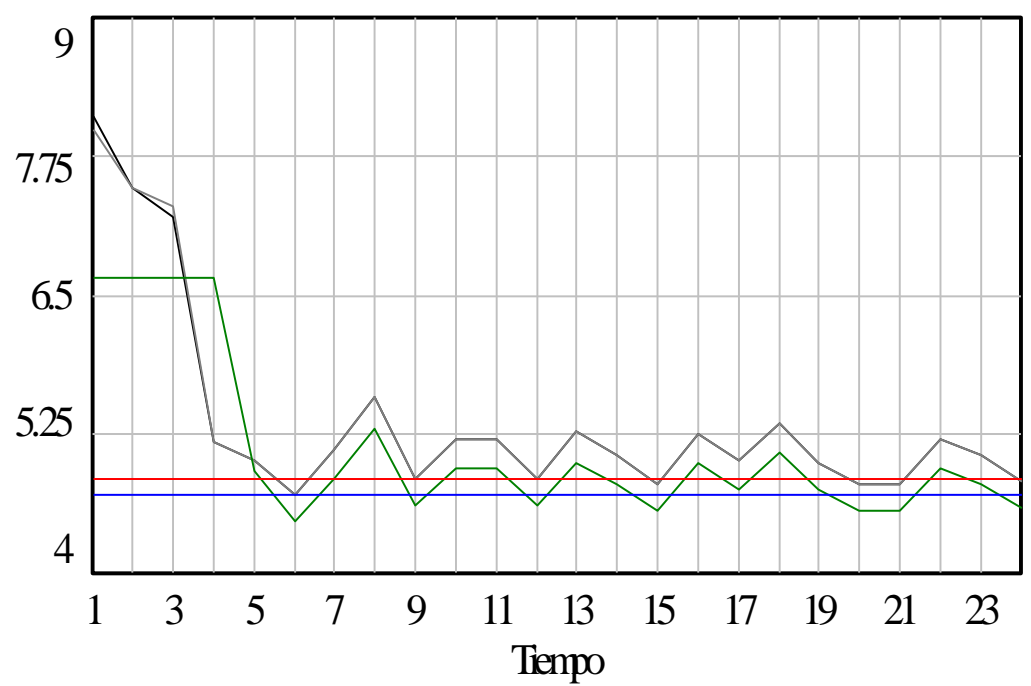

b)

Fig. 11. Resultados, producción. Fuente: elaboración propia.

\section{CONCLUSIONES}

Durante la revisión de literatura y las visitas de campo, se identificaron los comportamientos de la cultura local como uno de los elementos que influencian el alto porcentaje de los RAEE que se depositan en los vertederos, sean a cielo abierto o incinerados, sin alcanzar un mínimo proceso de tratamiento.
Los RAEE son también una oportunidad de negocio en los países en vía de desarrollo, entre otros, para el sector informal (recicladores que operan en calles, pequeños talleres o en sus propias casas), que podrían reciclarlos adecuadamente para no representar una pérdida de recursos, como ocurre actualmente. En Cali, el destino final de los RAEE es el relleno sanitario a cielo abierto, al sur de la ciudad, 
Validación de un modelo de logística inversa para la recuperación de los RAEE de la ciudad de Cali, basado en el Pensamiento Sistémico usando una simulación con Dinámica de Sistemas

que convierte este sector en una zona cada vez más nociva para el medio ambiente y la salud humana. Este problema se agrava si se considera el crecimiento de la ciudad hacia el sur. Con el tiempo, los desechos se convertirán en materiales que pueden haber sido aprovechados para la creación de nuevos productos.

Se reconoce que un sistema para la RAEE posee altos niveles de variabilidad e incertidumbre, lo cual lo vuelve complejo en su estudio o diseño. Esto hace necesario utilizar herramientas robustas como la dinámica de sistemas para la toma de decisiones a partir del reconocimiento de diferentes escenarios que se podrían presentar en el tiempo, con la información suministrada en la simulación.

A su vez, se determinó que la información actualmente disponible no permite caracterizar, con completa seguridad, un modelo de logística inversa.

Por esta razón, es necesario profundizar en este tipo de investigaciones para implementar propuestas de reciclado para estos desechos que crecen día a día. Dichas propuestas permitirían optimizar la recuperación de sus componentes y recuperar parte del valor de los mismos.

No obstante, en este estudio se ha diseñado un modelo de simulación de dinámica de sistemas en el software Vensim, que representa un sistema teórico de logística inversa. El modelo construido demuestra comportamientos coherentes en los resultados obtenidos.

Así mismo, este modelo representa, en primer lugar, las relaciones entre el mercado y el sistema productivo, y, a su vez, se asegura de tener presente la disyuntiva entre vender pellet o productos recuperados; en segundo lugar, representa las relaciones del sistema productivo propuesto, y finalmente, representa las relaciones entre el sistema productivo y de generación de RAEE. Estas relaciones permiten evidenciar comportamientos de elementos puntuales del sistema, dados los cambios en las condiciones del mercado de pellet y los productos recuperados y los cambios en la estructura productiva o del mercado generador de materias primas (RAEE). Todo esto sucede desde un enfoque sistémico, para lo cual se utilizan bucles sistémicos que representen las diferentes relaciones de los actores en el sistema, lo que valida la formulación cualitativa $y$ cuantitativa propuesta.

Esta primera aproximación permite iniciar el proceso para la formulación de un sistema de logística inversa en el tratamiento de los residuos que generan los aparatos de las tecnologías de la información. Se requiere, entonces, para trabajos futuros, definir rigurosamente los datos de generación de todos los tipos de RAEE, así como los otros parámetros del sistema. Con esto cubierto, el modelo propuesto puede ser usado para justificar comportamientos en este tipo de sistemas.

Igualmente, posteriores aplicaciones pueden orientarse a considerar el aprovechamiento de los elementos no plásticos de los RAEE, así como la utilización de recursos energéticos e hídricos en el sistema productivo.

\section{REFERENCIAS}

[1] J. Maier, "UNEP-United Nations Environment Programme", en A Concise Encyclopedia of the United Nations, Brill Nijhoff, 2010. pp. $712-714$.

https://doi.org/10.1163/ej.9789004180048.i962.612

[2] C. P. Balde, K. Ruediger, Blumenthal, S. Fondeur Gill, P. Kern, M., Micheli, E. Magpantay, y J. Huisman, E-waste statistics: Guidelines on classification, reporting and indicators. Bonn: United Nations University, 2015. Disponible en: URL

[3] L. M. U. Restrepo, S. M. Rodríguez, C. A. Hernández, y D. Ott, "Manejo de los RAEE a través del sector informal en Bogotá, Cali y Barranquilla," Waste, versión final, Abr. 2010. Disponible en: URL

[4] Departamento Nacional de planeacion, "Informe de Disposición Final de Residuos Sólidos," Superservicios superintendencia de servicos publicos Domiciliarios, Dic. 2017. Disponible en: $\underline{\mathrm{URL}}$ 
Validación de un modelo de logística inversa para la recuperación de los RAEE de la ciudad de Cali, basado en el Pensamiento Sistémico usando una simulación con Dinámica de Sistemas

[5] I. Roman, "eWaste en América Latina -El aporte de los operadores móviles en la reducción de la basura electrónica - Estudio de caso," GSMA Latino América, Feb. 2015. Disponible en: URL

[6] Departamento Administrativo de Planeación Municipal- DAPM, "Plan de Gestión Integral de Residuos Sólidos de Santiago de Cali," Plan de Gestión Integral de Residuos SólidosPGIRS, Dic. 2015. Disponible en: URL

[7] M. Y. Suarez Serrano, J. L. Tarazona Silva 2 y P. A. Triviño Quintero, "Diseño de un modelo de logística inversa para los RAEE tipo 3," en 2do Congreso Internacional en Administración de Negocios Internacionales. Universidad Pontificia Bolivariana, seccional Bucaramanga, 2017. Disponible en: URL

[8] G. E. V. Hernández, "Lineamientos para la gestión de RAEE de audio y video, a partir de la implementación de logística inversa, como herramienta de la responsabilidad extendida del productor," (Tesis de Maestría), Facultad de Estudios Ambientales y Rurales, Pontificia Universidad Javeriana, Bogotá, 2018. Disponible en: URL

[9] R. D. Shapiro, J. L. Heskett "Logistics Strategy: cases and concepts", St. Paul, Minnesota: West Publishing Company. 1985. Disponible en: URL

[10] L. C. Vellojín, J. C. M. González, y R. A. Mier, "Logística Inversa: una herramienta de apoyo a la competitividad de las organizaciones," Rev. Cientifica Ing. y Desarro., vol. 20, pp.184-202, Jul. 2006. Disponible en: URL

[11] S. Rubio Lacoba, "El sistema de Logística Inversa en la empresa: análisis y aplicaciones,"(Tesis Doctoral), departamento de economía aplicada y organización de empresas, Universidad de Extremadura, Cáceres, 2003. Disponible en: URL

[12] B. A. Díaz- Fernández, P. L. Gonzalez Torre, y M. J. Álvarez. Gil, Logística Inversa y medio ambiente. McGraw-Hill Interamericana de España, 2004.

[13] H.-Y. Kang y J. M. Schoenung, "Electronic waste recycling: A review of U. S. infrastructure and technology options", Resour. Conserv. Recycl., vol. 45, no. 4, pp. 368-400, Dec. 2005.

https://doi.org/10.1016/j.resconrec.2005.06.001

[14] Californians Against Waste (CAW), "Poison PCs and Toxic TVs: The Greatest Threat to the Environment You've Never Heard Of", Silicon Valley Toxics Coalition and Green Capitol. s.f. Disponible en: URL

[15] V. Pérez-Belis, M. D. Bovea, y V. IbáñezForés, "An in-depth literature review of the waste electrical and electronic equipment context: Trends and evolution," Waste Manag.
Res., vol. 33, no. 1, pp. 3-29, Jan. 2015. https://doi.org/10.1177/0734242X14557382

[16] F. Devesa, J. López, M. D. Samper, F. Parres, "Análisis del reciclado conjunto de ABS y HIPS obtenidos a partir de residuos eléctricos y electrónicos," en I Simposio Iberoamericano de Ingeniería de Residuos, Castellón, 2008. Disponible en: URL

[17] F. Blaser, "Gestión de residuos electrónicos en Colombia. Diagnóstico de electrodomésticos y de aparatos electrónicos de consumo", EMPA, ANDI, CNPML, Oct. 2009. Disponible en: URL

[18] Ministerio de Ambiente, Vivienda y Desarrollo Territorial, Dirección de Desarrollo Sectorial Sostenible, Principales Procesos Básicos de Transformación de la Industria Plástica y Manejo, aprovechamiento y disposición de Residuos Plásticos Postconsumo. Bogotá MAVDT 2004. Disponible en: URL

[19] A. N. Mashayekhi, "Transition in the New York State solid waste system: A dynamic analysis", Syst. Dyn. Rev., vol. 9, no. 1, pp. 23$47,1993$.

https://doi.org/10.1002/sdr.4260090103

[20] V. Sudhir, G. Srinivasan y V. R. Muraleedharan, "Planning for sustainable solid waste management in urban India", Syst. Dyn. Rev., vol. 13, no. 3, pp. 223-246, 1997. https://doi.org/10.1002/(SICI)10991727(199723)13:3<223::AIDSDR127>3.0.CO;2-Q

[21] O. Eriksson et al., "ORWARE, a simulation tool for waste management", Resour. Conserv. Recycl., vol. 36, n. ${ }^{\circ} 4$, pp. 287-307, Nov. 2002. https://doi.org/10.1016/S0921-3449(02)00031$\underline{9}$

[22] A. de C. Leal Neto, L. F. L. Legey, M. C. González-Araya, y S. Jablonski, "A System Dynamics Model for the Environmental Management of the Sepetiba Bay Watershed, Brazil," Environ. Manage., vol. 38, no. 5, pp. 879-888, Nov. 2006. https://doi.org/10.1007/s00267-005-0211-5

[23] N. Kollikkathara, H. Feng, y D. Yu, "A system dynamic modeling approach for evaluating municipal solid waste generation, landfill capacity and related cost management issues," Waste Manag., vol. 30, no. 11, pp. 2194-2203, Nov. 2010

https://doi.org/10.1016/j.wasman.2010.05.012

[24] A. van Schaik y M. A. Reuter, "Dynamic modelling of E-waste recycling system performance based on product design," Miner. Eng., vol. 23, no. 3, pp. 192-210, Feb. 2010. https://doi.org/10.1016/j.mineng.2009.09.004

[25] J. W. Forrester "The city. Urban dynamics.," Natl. Civ. Rev., vol. 58, no. 7, pp. 338-339, Jul. 1969.

https://doi.org/10.1002/ncr.4100580716 
Validación de un modelo de logística inversa para la recuperación de los RAEE de la ciudad de Cali, basado en el Pensamiento Sistémico usando una simulación con Dinámica de Sistemas

[26] J. Swanson, "Business dynamics. Systems thinking and modeling for a complex world", J. Oper. Res. Soc., vol. 53, no. 4. pp. 472-473, Abr.

2002. https://doi.org/10.1057/palgrave.jors.2601336

[27] K. E. Maani y R. Y. Cavana, Systems Thinking, System Dynamics: Understanding Change and Complexity. Ed 2, Pearson, 2007.

[28] G. Visconti, "Modeling the Environment," en: Problems, Philosophy and Politics of Climate Science. Springer Climate. Springer, Cham. pp. 31-47, 2018. https://doi.org/10.1007/9783-319-65669-4_3
[29] J. W. Morecroft, Strategic Modelling and Business Dynamics A feedback systems approach. Hoboken, NJ, USA: John Wiley \& Sons, Inc., 2015. Disponible en: URL

[30] J. J. M. Pardo Cordoba, "Modelo de Logística Inversa para la recuperación y aprovechamiento de residuos plásticos ABS en Cali," (Tesis de Maestría), Facultad de ingeniería, Universidad Autónoma de Occidente, Santiago de Cali, 2014. Disponible en: $\underline{\text { URL }}$ 